\title{
TÉCNICAS DE MANUFACTURA EN LA ESCULTURA PORTÁTIL OLMECA EN LA REGIÓN DE LA COSTA DEL GOLFO EN EL PERIODO FORMATIVO
}

\author{
MANUFACTURING TECHNIQUES OF THE OLMEC \\ PORTABLE SCULPTURE IN THE GULF COAST DURING \\ THE FORMATIVE PERIOD
}

\section{Henri Bernard Medina ${ }^{1}$}

henribernard@hotmail.com

\section{RESUMEN}

La escultura portátil olmeca abarca figurillas, hachas votivas, máscaras, pectorales y cetros. Junto con otros ornamentos, como cuentas y orejeras, fue realizada principalmente en serpentina; sin embargo, también emplearon jadeíta. Muchas de estas piezas llegaron a colecciones dentro y fuera de México sin un contexto preciso de procedencia y muchas veces no cuentan con un análisis adecuado de composición mineralógica. En este trabajo presentaremos las primeras manifestaciones de este tipo de escultura halladas en contextos arqueológicos dentro de sitios Olmecas de la Costa del Golfo, a través del análisis de sus técnicas de manufactura.

Palabras clave: Olmeca, tecnología, lapidaria.

\footnotetext{
${ }^{1}$ Museo de Antropología de Xalapa, Departamento de Análisis Arqueométricos, Universidad Veracruzana.
} 


\section{ABSTRACT}

The Olmec portable sculpture encompasses figurines, votive axes, masks, pectorals and scepters. Along with other ornaments, such as beads and earspools, the Olmec crafted them mainly in serpentine; however, they also used jadeite. Many of these pieces reached collections inside and outside Mexico without an accurate context of provenance and often do not have mineralogical analysis to identify the raw materials. In this work, I will present the first manifestations of this type of sculpture found in archaeological contexts within Olmec sites of the Gulf Coast through technological analysis of the manufacturing traces.

Palabras clave: Olmec, technology, lapidary.

\section{CONTEXTO DE LA INVESTIGACIÓN}

Cuando pensamos en los olmecas, de manera general, nos remitimos inevitablemente a su escultura monumental en piedra, sobre todo a las famosas cabezas colosales. Sin embargo, es conocida, aunque en menor proporción, por su particular trabajo en la escultura portátil generalmente realizadas en rocas metamórficas. Curiosamente, fue sobre un conjunto de este tipo de escultura, de donde surgiría la definición de estilo olmeca. En esta investigación mostraremos algunas de las técnicas utilizadas en su manufactura.

La definición del estilo olmeca se basó sobre en un conjunto de piezas de formato pequeño que se encontraban en diversas colecciones de México y el mundo a finales del siglo XIX y principios del $\mathrm{XX}$, de las cuales algunos autores distinguieron rasgos estilísticos particulares que las diferenciaban de los estilos de otras culturas prehispánicas mejor conocidas hasta el momento, esto originó un nuevo conjunto 
estilístico denominado como olmeca (BEYER, 1927; SAVILLE, 1929; VAILLANT, 1932).

Al inicio de la definición no se tenía conocimiento de la temporalidad ni la ubicación precisa de dónde procedían estas esculturas, ya que las observaciones realizadas fueron descripciones formales de las piezas. Sería hasta mediados del siglo XX cuando se realizaron las primeras excavaciones arqueológicas en la Costa del Golfo por parte de Mathew Stirling (1939) y Phillip Drucker (1952) cuando se pudieron encontrar en contexto arqueológico varias esculturas portátiles del llamado estilo olmeca y precisar la ubicación y la temporalidad de la denominada cultura olmeca. Ésta fue una de las primeras sociedades complejas en Mesoamérica, la cual floreció en el Golfo de México, en los actuales Estados de Veracruz y Tabasco, durante gran parte del Periodo Formativo entre el 1800 al 400 a. C.

Ahora a más de 100 años de las primeras descripciones del estilo escultórico en piedra denominadas como olmeca, contamos con un acervo más extenso de piezas encontradas en excavaciones controladas dentro de proyectos arqueológicos que nos permiten ubicarlas espacial y, en algunos casos, temporalmente. El estudio de estos artefactos había sido abordado, principalmente como lo comentamos anteriormente, desde una perspectiva formal. En contraste, pocos son los trabajos que han tenido alguna aproximación al estudio de las técnicas de manufactura de estos objetos y que, además, procedan de excavaciones arqueológicas controladas. 
En este trabajo haremos un compendio sobre el análisis tecnológico de artefactos procedentes de cuatro sitios arqueológicos de la Costa del Golfo con la finalidad de observar cambios y continuidades en las técnicas de manufactura.

El universo de estudio es de un total de 71 Artefactos: 37 de San Lorenzo, 15 de Loma del Zapote, 7 de La Venta y 12 de Arroyo Pesquero (Figura 1). Para su análisis se dividió en cuatro grupos formales: figurillas, hachas, máscaras y varios. En este último están pectorales, cuentas, orejeras y punzones, entre otros; por lo que este grupo es el más numeroso con 44 artefactos, seguido por el grupo de las hachas con 17 , luego el de las máscaras con $7 \mathrm{y}$, por último, el de las figurillas con 3 ejemplares.

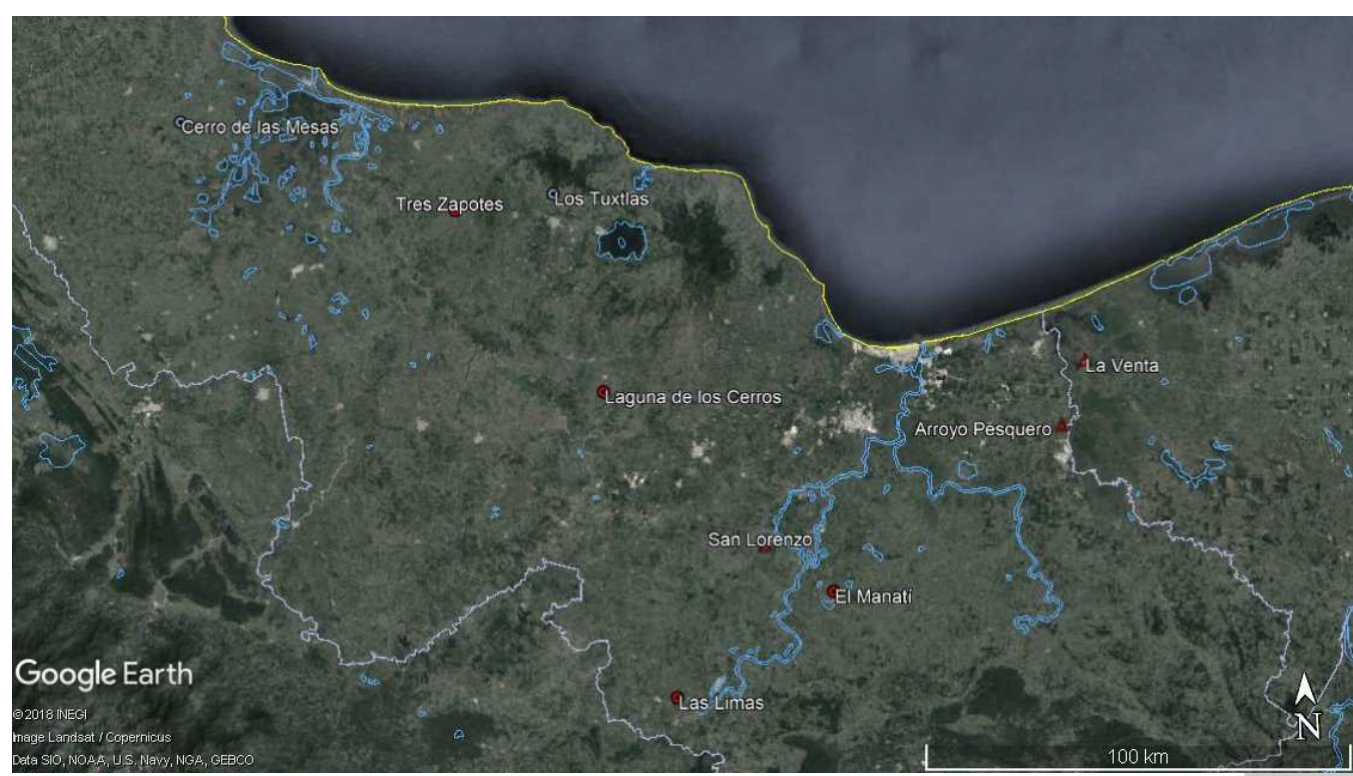

Figura 1. Mapa de ubicación de sitios referido en el texto. 
Tenemos las fechas absolutas para los sitios de San Lorenzo y Loma del Zapote, gracias al proyecto Arqueológico San Lorenzo Tenochtitlán (PASLT) dirigido por Ann Cyphers (CYPHERS et al., 2013). También, para el sitio de La Venta se tienen los datos de Stirling (1943) y Drucker (DRUCKER et al. 1952; 1959) a mediados del siglo XX y más tarde por los datos recabados por Rebecca González Lauck (1990). Lamentablemente para el sitio de Arroyo Pesquero no contamos con un fechamiento absoluto; ya que el contexto del hallazgo no se puede fechar con precisión. Sin embargo, lo ubicamos de manera relativa por el estilo escultórico para el Periodo Formativo Medio (900-400 a.C.), pero las 12 piezas de este sitio hay que tomarlas con reserva en cuanto a la temporalidad.

La cronología de las piezas analizadas la podemos ver en la Tabla 1 en la que se aprecia que la gran la gran mayoría (36) proceden de los sitios de San Lorenzo y Loma del Zapote de la fase San Lorenzo B (1200-1000 a.C.). 


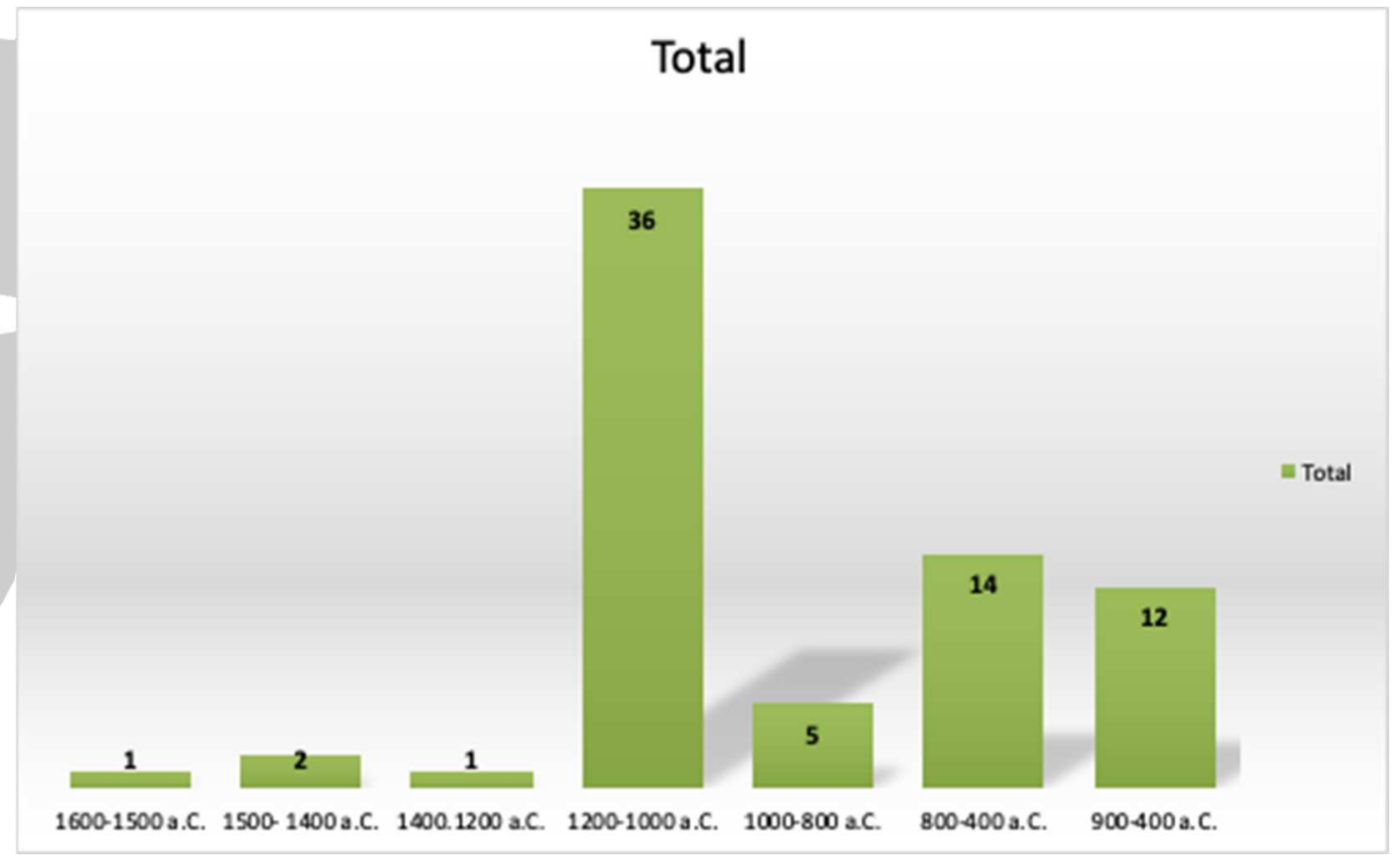

Tabla 1. La cronología de los objetos analizados. Los 12 que están entre 900-400 a.C. son del sitio de Arroyo Pesquero que sólo cuentan con cronología relativa.

\section{METODOLOGÍA DE ESTUDIO}

La metodología empleada en el análisis de las huellas de manufactura cuenta con varios pasos (MELGAR, 2004; MELGAR Y SOLÍS, 2010; BERNARD, 2018; MELGAR et al., 2018). El primer acercamiento a la pieza es un análisis macroscópico a simple vista o con ayuda de una lupa con un aumento de 20x. Ello nos permite obtener las primeras pistas de los instrumentos utilizados. El segundo paso se lleva a cabo con la ayuda de un microscopio estereoscópico con cámara 
incluida, bajo el cual se observa el material con un aumento de 30X y se digitalizan las imágenes. Esto permite comparar con mejor detalle las micro huellas arqueológicas observadas sobre aspectos de regularidad de la superficie y del borde, la presencia de líneas o no, su separación y dirección. El tercer paso es la obtención de una impresión con ayuda de una cinta de polímero recortada en rectángulos de alrededor de $5 \mathrm{~mm}$ X $6 \mathrm{~mm}$, impregnada de acetona, la cual se presiona en la superficie del objeto. Una vez retirada la impresión obtenida, la muestra es observada bajo el microscopio electrónico de barrido (MEB) en el cual se analizan con aumentos de 100x, 300x, 600x et 1000x. Las huellas observadas en las imágenes digitales se comparan con las huellas realizadas con material experimental, lo que nos permite confirmar o excluir herramientas de trabajo y conocer la naturaleza de la última fase de la cadena de producción.

\section{Materiales analizados}

\section{San Lorenzo y Loma del Zapote}

San Lorenzo considerada como la primera capital Olmeca, fue el centro más influyente en la costa sur del Golfo en el Formativo temprano y su ubicación en el antiguo río Coatzalcoalcos proporcionó una ventaja para la participación comercial regional e interregional. La fase San Lorenzo B (1200-1000 a.C.) representa el momento de máximo esplendor de San Lorenzo (CYPHERS et al., 2013: 107). Loma de Zapote, por el contrario, fue un sitio secundario con mayor actividad al decaer el sitio de San Lorenzo, para las fases Nacaste y Palangana. 
El objeto más antiguo de la colección analizada es una cuenta que proviene de la Fase Bajío y los más tardíos proceden de contextos de la fase Palangana. Hay que tomar en cuenta que las etapas más tempranas han sido poco excavadas debido, principalmente, a la profundidad en la que se encuentran estos vestigios. La fase San Lorenzo B es donde se concentra la mayor cantidad de objetos marcando una diferencia altamente superior a las otras fases, para el sitio de Loma del Zapote la mayor representatividad se da para la fase Palangana.

De San Lorenzo tuvimos acceso a 37 piezas: 7 hachas, 1 fragmento de máscara y 29 objetos diversos. Dentro de estos últimos encontramos lo siguiente: 9 posibles pectorales o adornos, 4 orejeras, 4 cuentas, 4 núcleos de perforación, 2 punzones, 2 teselas, 1 bloque multiperforado, 1 preforma de cuenta, 1 preforma de orejera y 1 no identificado. Desde la fase Bajío (1600-1500 a.C.) hasta la fase Nacaste (1000800 a. C.), como puede verse en la Tabla 2.

De Loma del Zapote, el corpus es de 15 piezas: 4 hachas y 11 del grupo de diversos divididos en 2 posibles pectorales o adornos, 2 orejeras, 4 cuentas, 1 preforma de cuenta,1 tesela y 1 lasca. Desde la fase San Lorenzo B (1200-1000 a.C.) hasta la fase Palangana (800-400 a.C.). Tanto para el sitio de Loma del Zapote como para San Lorenzo hasta la fecha no se reportan figurillas encontradas en excavaciones controladas. 


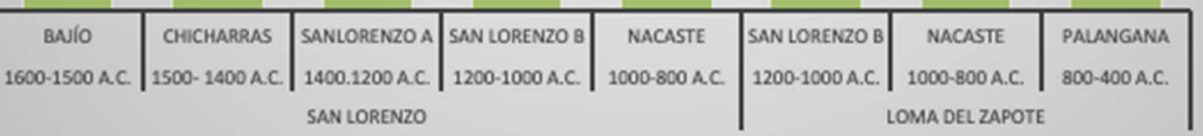

Tabla 2. Cronología de los objetos de San Lorenzo y Loma del Zapote.

\section{Las hachas}

Las hachas del sitio de San Lorenzo van desde la fase Chicharras (1500 - 1400 a.C) a la fase San Lorenzo B (1200- 1100 a. C.). Las hachas de Loma del Zapote aparecen desde San Lorenzo B hasta la fase Palangana (800-400 a.C.) (Tabla 3). 


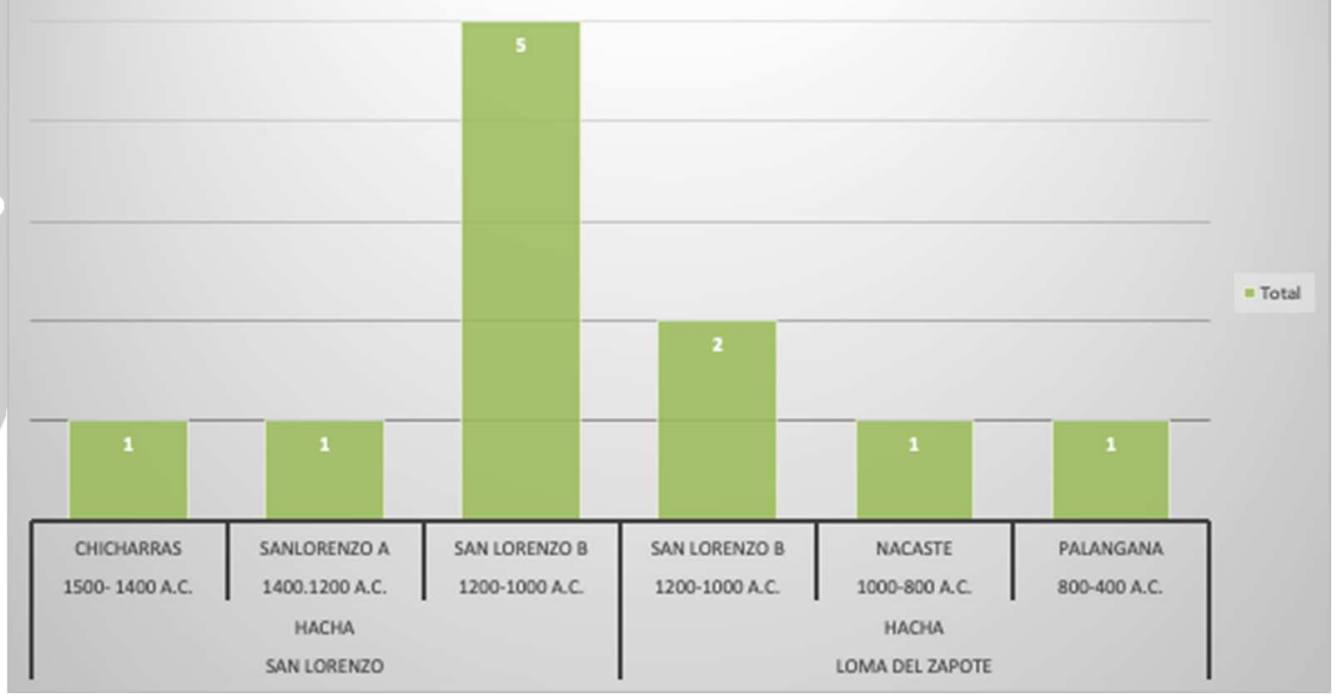

Tabla 3. Hachas de San Lorenzo y Loma del Zapote por fase.

El hacha más temprana que tenemos en este trabajo J1482 (Fase Chicharras), presenta huellas de desgaste con basalto y pulido con arenisca gruesa, mientras que para el hacha J13-1516 (Fase San Lorenzo A), observamos un desgaste con caliza, pulido con arenisca y bruñido con piel. Para las 7 hachas de la Fase San Lorenzo B Tenemos que tanto las 5 hachas de San Lorenzo como las de Loma del Zapote (J1064, J171, J952, J742, J1015 y J1065) presentan las bandas de $100 \mu \mathrm{m}$ características de desgaste con basalto (Figura 2). En algunos casos se ve que hay 
un pulido con arenisca y empezamos a ver algunas huellas de pulido con jade en la J171 y la J1065 (Fase San Lorenzo B).
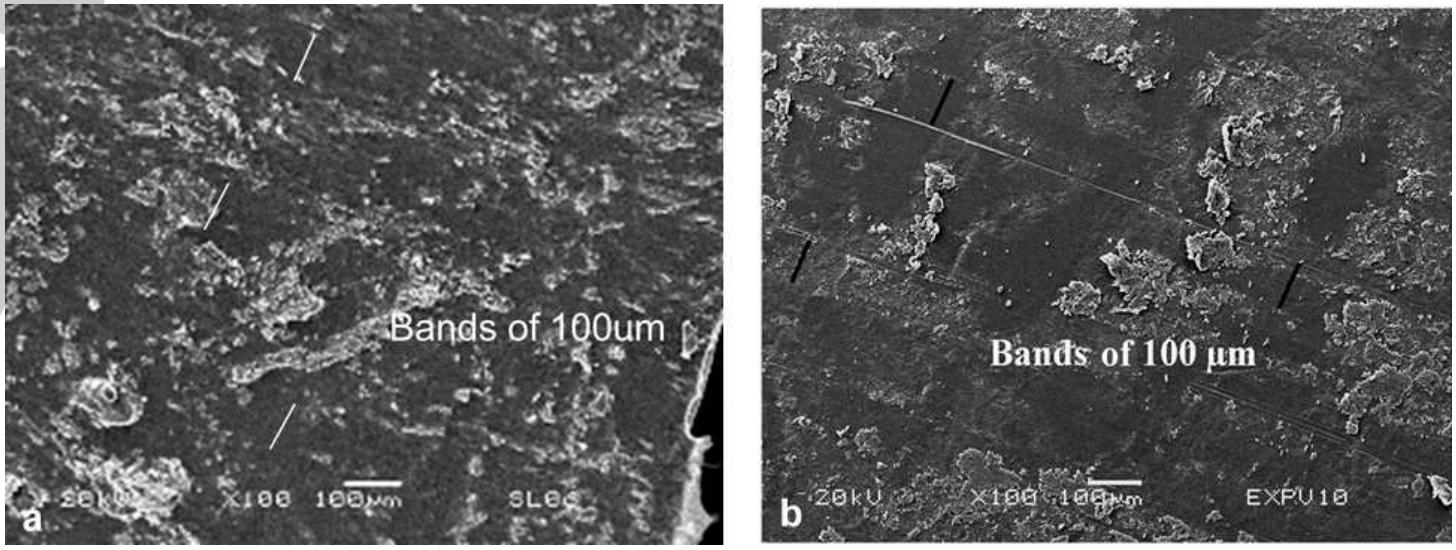

Figura 2. Análisis de huellas de superficies: hacha J952 (a) comparada con el desgaste experimental con basalto (b).

\section{Máscara}

El fragmento de máscara de rasgos similares a la reportada por Drucker (1952: plate 66) para el sitio de Tres Zapotes. El análisis de la técnica de manufactura presentó en su superficie desgaste y pulido con arenisca (Figura 3). La perforación encontramos, como en la mayoría de las piezas de San Lorenzo, fue hecha con un instrumento tubular como carrizo y abrasivos en este caso parece la utilización de algún tipo de arenas por la textura rugosa y líneas de alrededor de $1.3 \mu \mathrm{m}$ que se 
aglomeran para formar bandas de $10 \mu \mathrm{m}$ (Figura 4). Las muestras de los cortes de la máscara no fueron concluyentes.
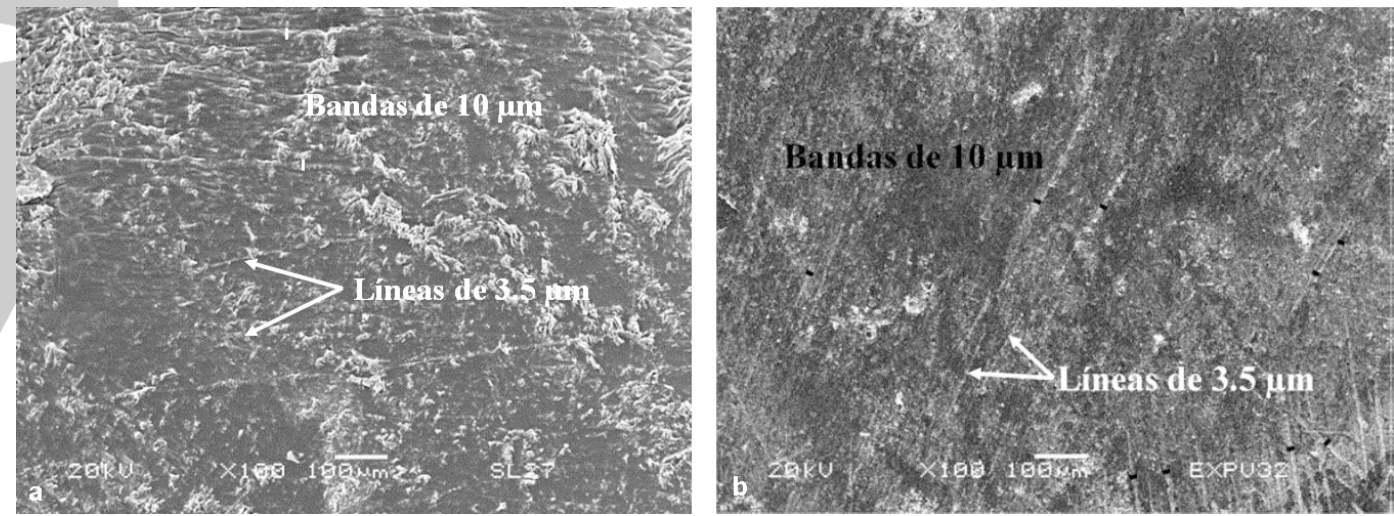

Figura 3. Análisis de huellas de superficies: máscara (a) comparada con el desgaste experimental con arenisca (b).
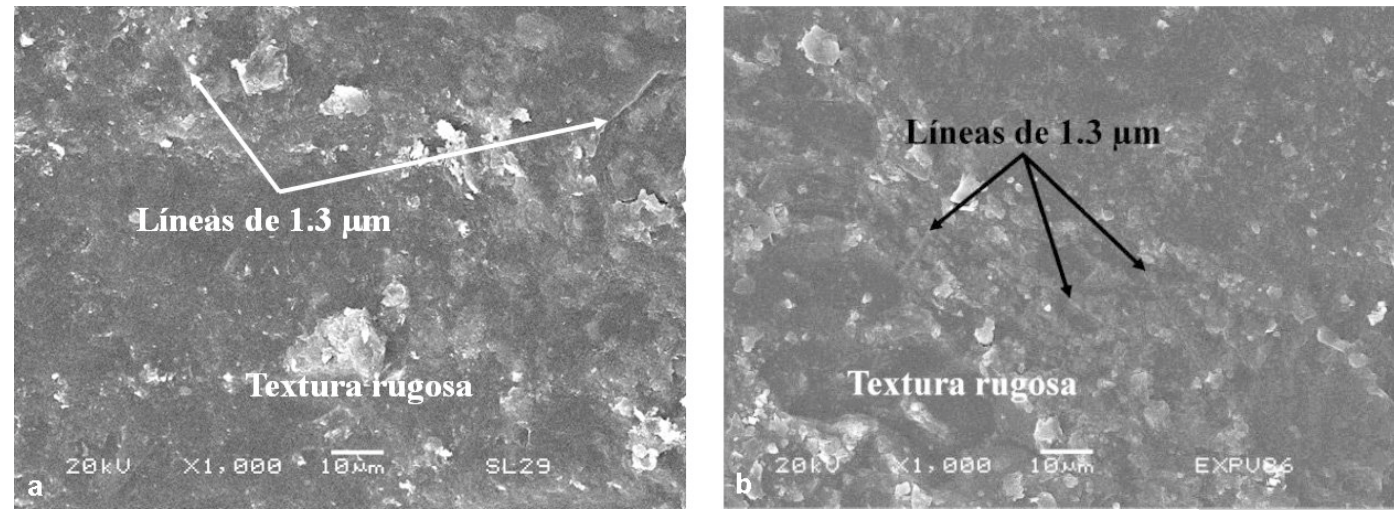

Figura 4. Análisis de huellas de perforaciones: máscara (a) comparada con horadación experimental con arena y carrizo (b). 


\section{Cuentas}

Las cuentas totales encontradas son 10: 4 en San Lorenzo y 6 en Loma del Zapote. Las de San Lorenzo, la muestra más antigua es la J217 encontrada en la cima de la meseta en la unidad SL-53 en un contexto ceremonial de la fase Bajío. Su superficie fue desgastada con arenisca por las bandas de $10 \mu \mathrm{m}$ (Figura 5a) y la perforación bicónica realizada con algún instrumento tubular y abrasivos. Las perforaciones, como son el caso de todas las observadas para San Lorenzo, presentan mucha textura por conservar la tierra en las que fueron encontradas. Con el sentido de respetar estas impurezas se tomó una muestra por pieza en la zona que menos residuos presentaba. Lo que no permitió dar una observación concluyente.

Las otras 3 cuentas localizadas en San Lorenzo son de la fase San Lorenzo B, al igual que la anterior proviene de la cima de la meseta, 2 de contextos habitacionales y la otra de contexto ceremonial, todas presentan desgaste en arenisca por las bandas de $10 \mu \mathrm{m}$ (Figura 5b). Las perforaciones como son el caso de todas de San Lorenzo presentan mucha textura; sin embargo, hay dos casos claros, las cuentas J001 y J259 presentan huellas de la utilización de instrumentos tubulares como carrizos con abrasivos de arenas en sus perforaciones.

De las cuentas de Loma del Zapote (J156, J160, J941, J028, J258y J260), las 3 primeras fueron encontradas en contextos ceremoniales de la fase San Lorenzo B y las otras 3 de contextos habitacionales para la Fase Palangana (800-400 a.C.) 

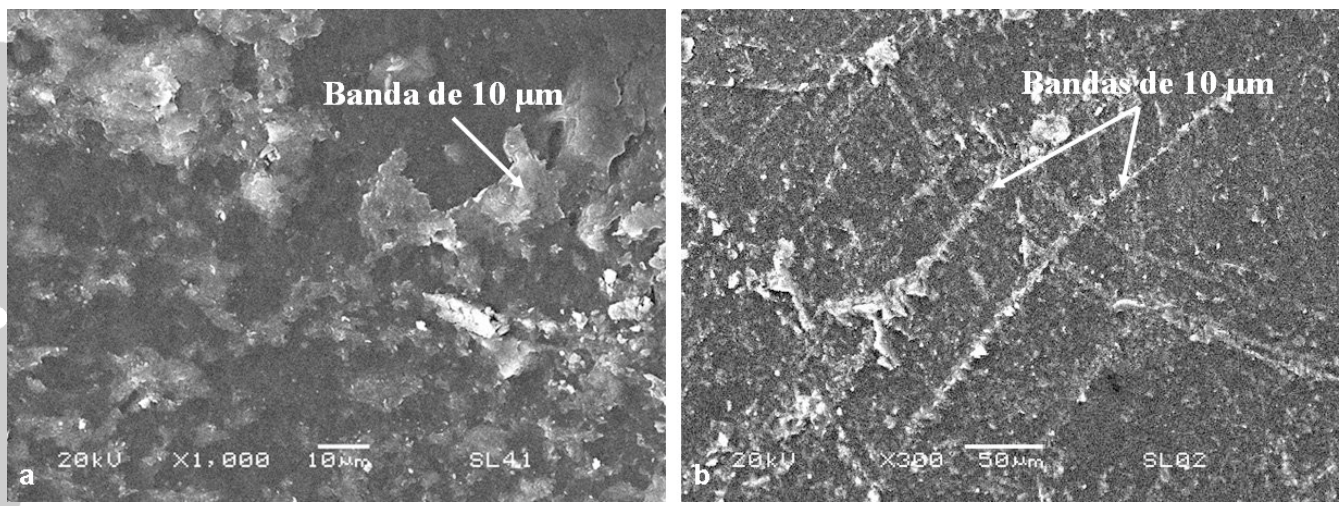

Figura 5. Análisis de superficies de cuenta J217 (a) y de cuenta J160 (b).

La superficie de la J156 de contexto ceremonial aparece con huellas de manufactura de arenisca, pulida con jade y bruñido con piel. Las demás presentan, al igual que las cuentas de San Lorenzo, pulidos con arenisca y perforaciones con abrasivos.

Para las orejeras encontramos 7 en total, 4 en San Lorenzo de la misma fase y en Loma del Zapote 3 orejeras de diferentes fases todas en contextos habitacionales. Solamente pudimos apreciar la superficie, de las 7 piezas la se observó que el uso de areniscas en el pulido sigue siendo una constante, aunque se aprecian diferentes calidades en los granos (Figura 6). Por su parte, en el bruñido hubo un poco de diferencias algunas con mejores acabados donde se observa el uso de piel para dejar un aspecto lustroso. 

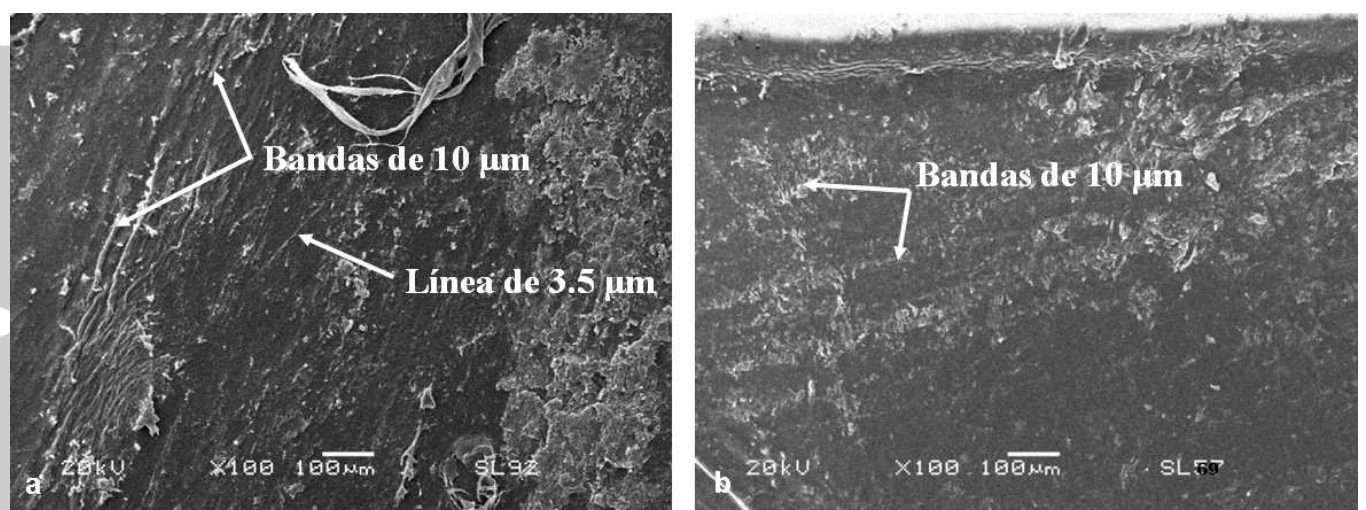

Figura 6. Análisis de superfícies de orejera J177 de la fase San Lorenzo B (a) y orejera J022 de la Fase Palangana (b).

Los pectorales o adornos analizados fueron 11 principalmente de la Fase San Lorenzo B. El más antiguo es de la fase Chicharras, con forma de lengüeta, se encontró fragmentada, (J579 J580). Hay una placa, muy porosa de la fase San Lorenzo A procedente del Palacio rojo, por las condiciones de la placa no se pudo tomar una muestra para analizar sus técnicas de manufactura. También hay 3 piezas en forma de colmillo, uno de forma trapezoidal con acanaladuras pequeñas en las esquinas, otra lengüeta como la de la fase Chicharras, una pieza multiperforada y dos pectorales fragmentados.

Las superficies examinadas de los pectorales arrojaron que la mayoría, 7 de ellas fue pulida con areniscas, principalmente de grano grueso (J579, J1052, J085, J1150, J154, J1135), solo una de arenisca fina (J172). En el sitio de Loma del Zapote solo tenemos reportadas 2 en contextos habitacionales, uno en forma de colmillo y el 
otro fragmentado sin forma clara. Las cuales no arrojaron muestras concluyentes en cuanto a la técnica de manufactura.

En el sitio de San Lorenzo, se encontraron algunos fragmentos de lo que parecen ser agujas o perforadores, se sabe de la utilización de perforadores por los olmecas por varias evidencias encontradas en La Venta (DRUCKER, 1952: plate 53), precisamente una de esas piezas será analizada en los materiales de dicho sitio. Los tres objetos de San Lorenzo son elementos cilíndricos, uno claramente presenta la punta afilada y todos son de la fase San Lorenzo B. Parece resultado de un núcleo de perforación para luego ser trabajados y afilados como perforadores, en ellos se observa que la superficie de textura rugosa fue desgastada con abrasivos finos que contenían polvo de jadeíta (Figura 7).
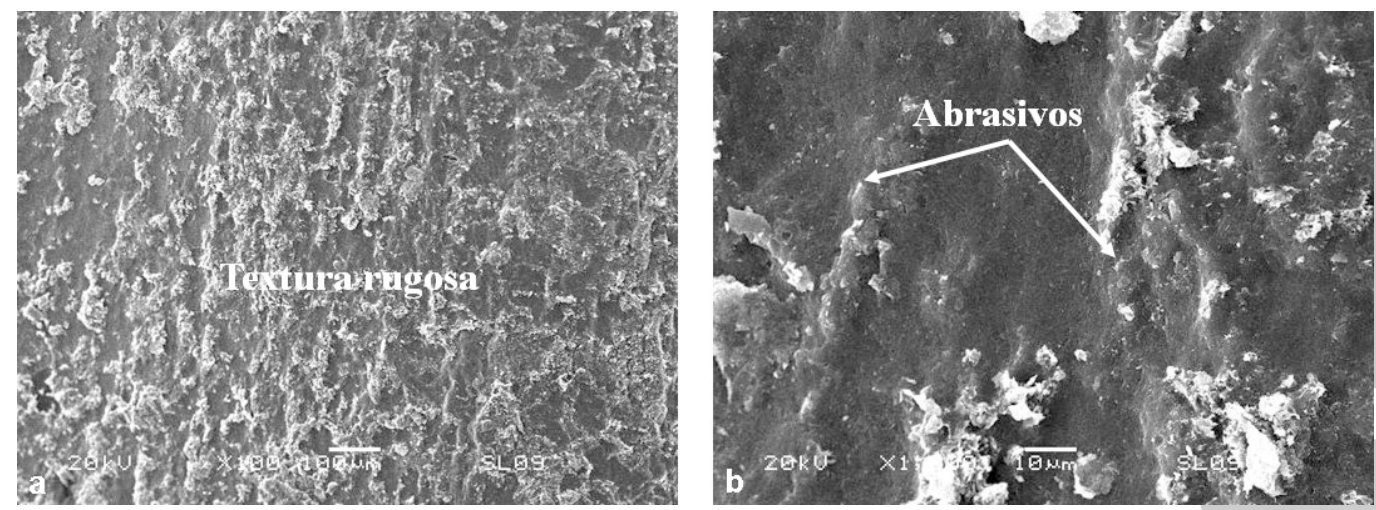

Figura 7. Superficie del perforador J501 (a), la cual fue desbastada con abrasivos que contenían polvo de jadeíta (b). 
Se encontraron 4 núcleos de perforación en el sitio de San Lorenzo, de la fase San Lorenzo B. En cuanto a las técnicas empleadas para sacar los núcleos de perforación podemos decir que las superficies de todas presentan huellas de uso de abrasivos (Figura 8). En una de ellas queda claro que en los abrasivos existían algunos cuarzos. Los cortes no pudieron ser determinados ya que las muestras presentaron mucha textura.

Hay una lasca de piedra verde en Loma del Zapote para la fase Nacaste, en contexto habitacional, insuficiente para hacer cualquier tipo de conjetura sobre un posible sitio de producción.
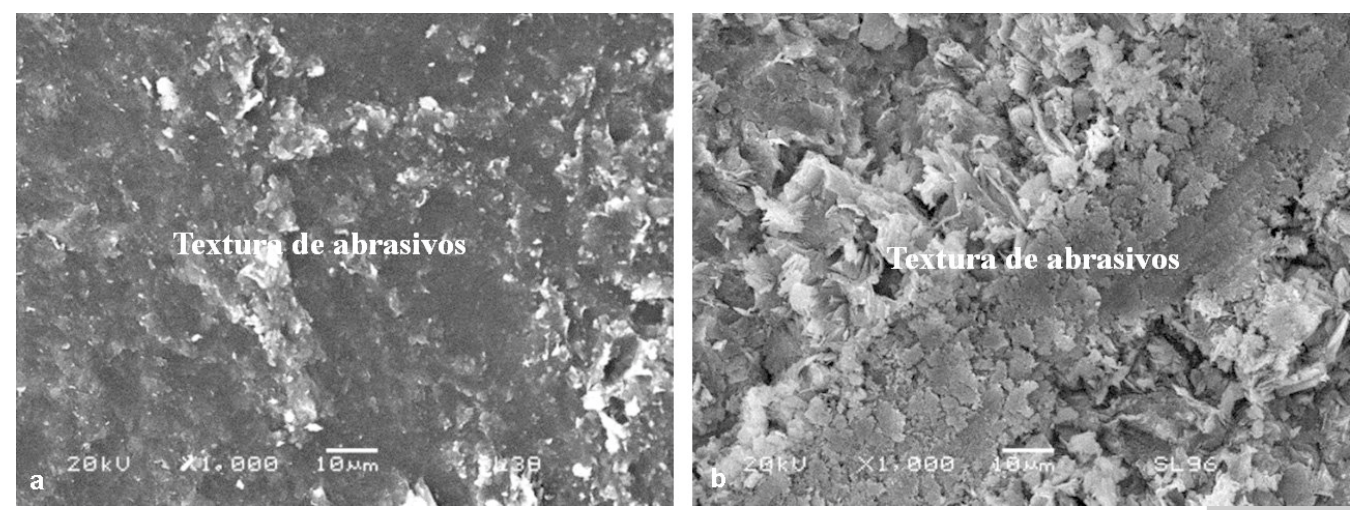

Figura 8. Huellas de abrasivos en las superficies cilíndricas de los núcleos de perforación (a), al parecer de granos de cuarzo (b). 


\section{La Venta}

De las piezas de La Venta en el Museo Nacional de Antropología tuvimos acceso a 7 (Tabla 4): 1 figurilla, 4 hachas, 2 objetos diversos entre ellos un pectoral y un mango de perforador. Todos procedentes del complejo A de la Venta, de excavaciones en contextos ceremoniales y que formaban parte de ofrendas, de la Fase I (1000-900 a.C.), Fase III (800-700 a.C.) y Fase IV (700-600 a.C.).

El sitio de la Venta está localizado al oeste del Estado de Tabasco. Cubría una extensión de alrededor de 200 hectáreas. En la actual área protegida se encuentran 9 conjuntos arquitectónicos con áreas exclusivas de residencia y con funciones cívicos ceremoniales (GONZÁLEZ, 1994: 96). El conjunto más pequeño e investigado hasta la fecha es el complejo A, el cual ha arrojado una gran cantidad de ofrendas y objetos algunos de los cuales formaron parte del corpus analizado en este trabajo. 


\begin{tabular}{|c|c|c|c|c|c|c|c|c|}
\hline Id & Inv. & Forma & Procedencia & Foto & Alto $\mathrm{cm}$ & Largo $\mathrm{cm}$ & Ancho cm & Descripción de hallazgo \\
\hline 1 & 103088 & Pectoral & La Venta & & 4.9 & 5.3 & 2.1 & $\begin{array}{l}\text { Complejo A; Ofrenda 7: máscara } \\
\text { miniatura/ornamento. Fase I (1000 } \\
900 \text { a.C.) }\end{array}$ \\
\hline 2 & 103069 & Hacha & La Venta & & 17 & 7.2 & & $\begin{array}{l}\text { Complejo A; Ofrenda } 2 \text { Fase III } \\
(800-700 \text { a.C. })\end{array}$ \\
\hline 3 & 103062 & Figurilla & La Venta & & 11.1 & 3.3 & 1.1 & $\begin{array}{l}\text { Complejo A; Tumba A, bulto } \\
\text { mortuorio II. Fase IV (700-600 } \\
\text { a.C.) }\end{array}$ \\
\hline 4 & 103097 & $\begin{array}{l}\text { Mango } \\
\text { de } \\
\text { punzón }\end{array}$ & La Venta & & 9.5 & 3.01 & 2.7 & $\begin{array}{l}\text { Complejo A; Tumba A, bulto } \\
\text { mortuorio II. Fase IV (700-600 } \\
\text { a.C.) }\end{array}$ \\
\hline 5 & 103068 & Hacha & La Venta & & 14.9 & 7.9 & 3.5 & $\begin{array}{l}\text { Complejo A; Ofrenda 1942-B. } \\
\text { Fase IV (700-600 a.C.) }\end{array}$ \\
\hline 6 & 107468 & Hacha & La Venta & & 14 & 6.5 & 3.7 & $\begin{array}{l}\text { Complejo A; Ofrenda 1942-B; } \\
\text { Fase IV (700-600 a.C.) }\end{array}$ \\
\hline 7 & 109623 & Hacha & La Venta & & 14.7 & 8.1 & 3.9 & $\begin{array}{l}\text { Complejo A; Ofrenda 1942-B; fase } \\
\text { IV (700-600 a.C.) }\end{array}$ \\
\hline
\end{tabular}

Tabla 4. Objetos analizados del acervo del MNA.

Los 7 artefactos de la Venta se encontraron en las excavaciones del Complejo A, 5 de ellas de la temporada de campo de1942 y las otras 2 de 1955. La mayoría ubicadas en la Fase IV, un ejemplo de la Fase I y otro de la Fase III.

Empezaremos con la pieza más antigua del corpus, un pectoral de un rostro antropozoomorfo encontrado dentro de la ofrenda 7 (Figura 9). Esta pieza es interesante ya que parece estar en proceso de elaboración. Presenta diversas perforaciones en el contorno. Es una técnica de corte mencionada en diversos trabajos (CHENAULT, 1986; MELGAR Y SOLÍS, 2010). La cual consiste en hacer una serie de perforaciones cercanas unas con otras para luego eliminar los puntos de contacto 
por medio de una piola. En la parte trasera del rostro presenta una horadación que abarca la mayor parte de la pieza, al final de está hay una pequeña perforación que sale por la parte frontal a la altura de la punta de la nariz. Los rasgos del rostro apenas son esbozados. Presenta algunas incisiones en el rostro y a la altura de la boca se observan dos inicios de perforación para delimitarla.
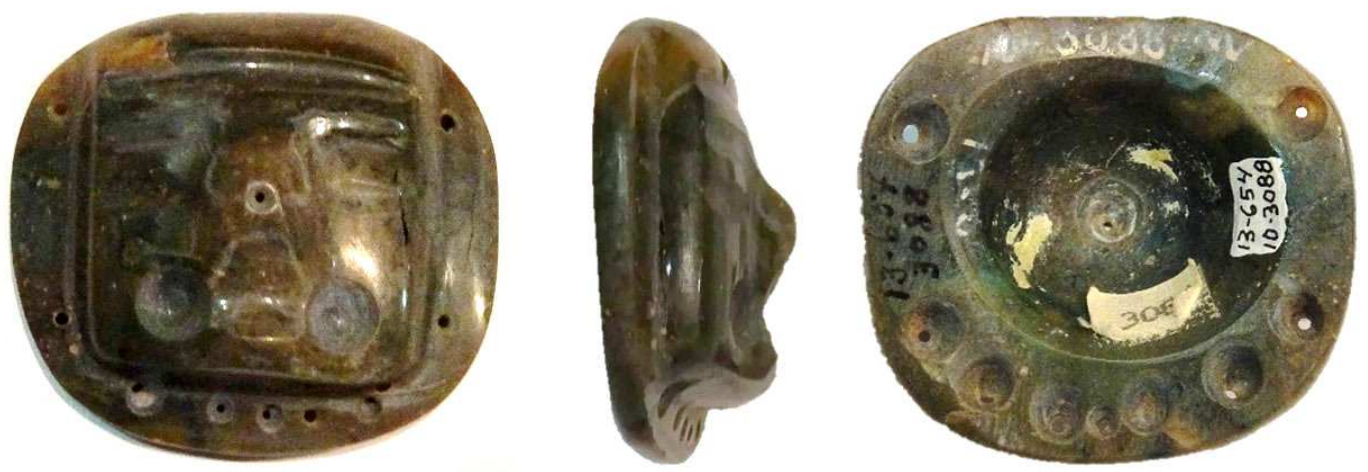

Figura 9. Pectoral de la ofrenda 7.

Para Drucker, el rostro del pectoral lo identifica como el de un jaguar y observa que es difícil saber si la pieza no estaba completamente terminada o es para ser vista muy esquematizada. El pectoral presenta en la superficie lisa bandas de 10 a $15 \mu \mathrm{m}$ y líneas en distintas direcciones de $3.5 \mu \mathrm{m}$ y $10 \mu \mathrm{m}$ de espesor características de desgaste y pulido con arenisca (Figura 10), el bruñido fue realizado con piel dejando la superficie poco rugosa. 


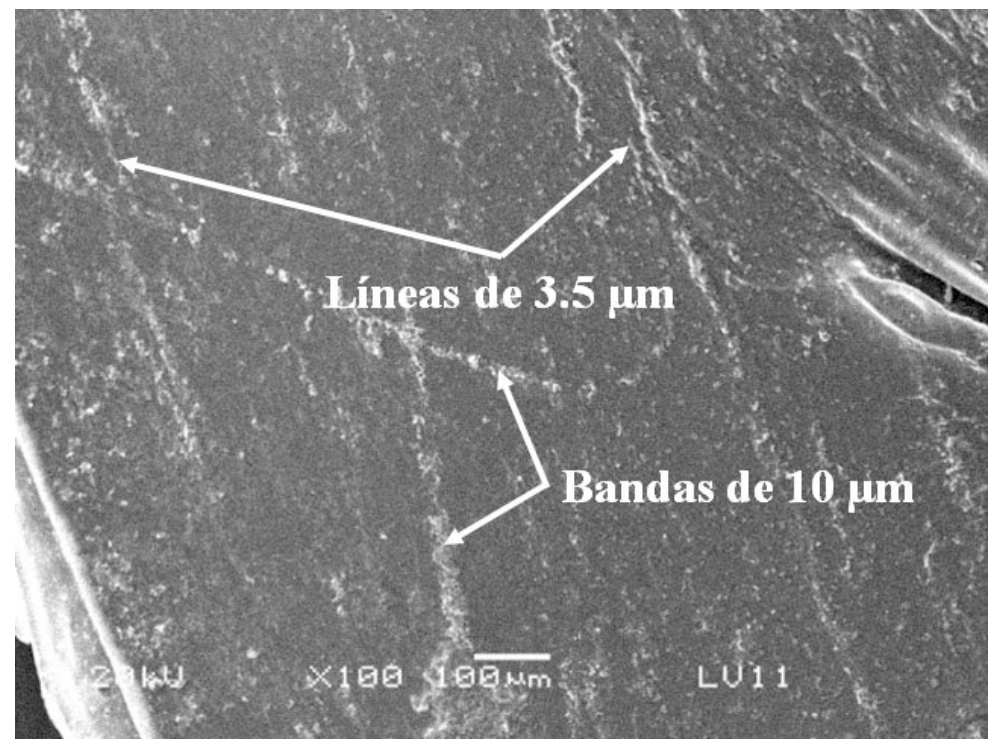

Figura 10. Superficie del pectoral de La Venta.

Las muestras de las incisiones en su mayoría no fueron claras, sin embargo, podemos distinguir el uso de la obsidiana en su manufactura (Figura 11). Por su parte, la perforación que se encuentra en la parte trasera del rosto muestra claramente el uso de abrasivos de diferentes dimensiones.

La segunda pieza del acervo, es un hacha que se encontró en la ofrenda 2 dentro de las excavaciones realizadas en La Venta en 1955 (Figura 12), la cual se ubicó en la línea central del complejo A al sur del montículo A-2 (Mound A2) es de la Fase III (DRUCKER et al., 1959). 

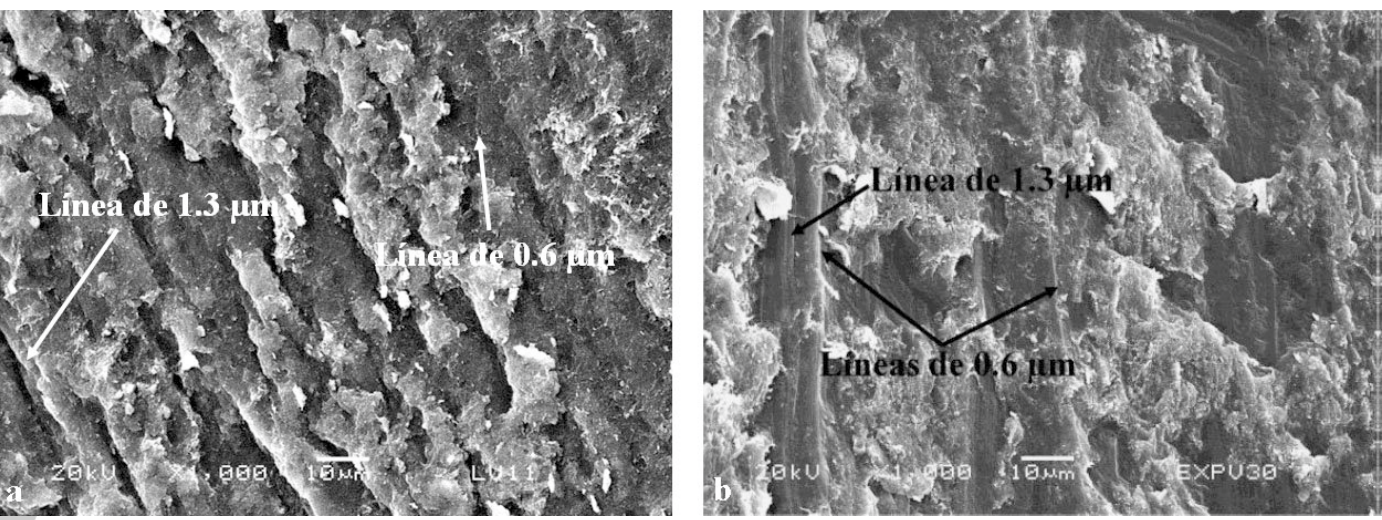

Figura 11. Análisis de las incisiones del pectoral (a) comparadas con diseños incisos experimentales hechos con obsidiana.
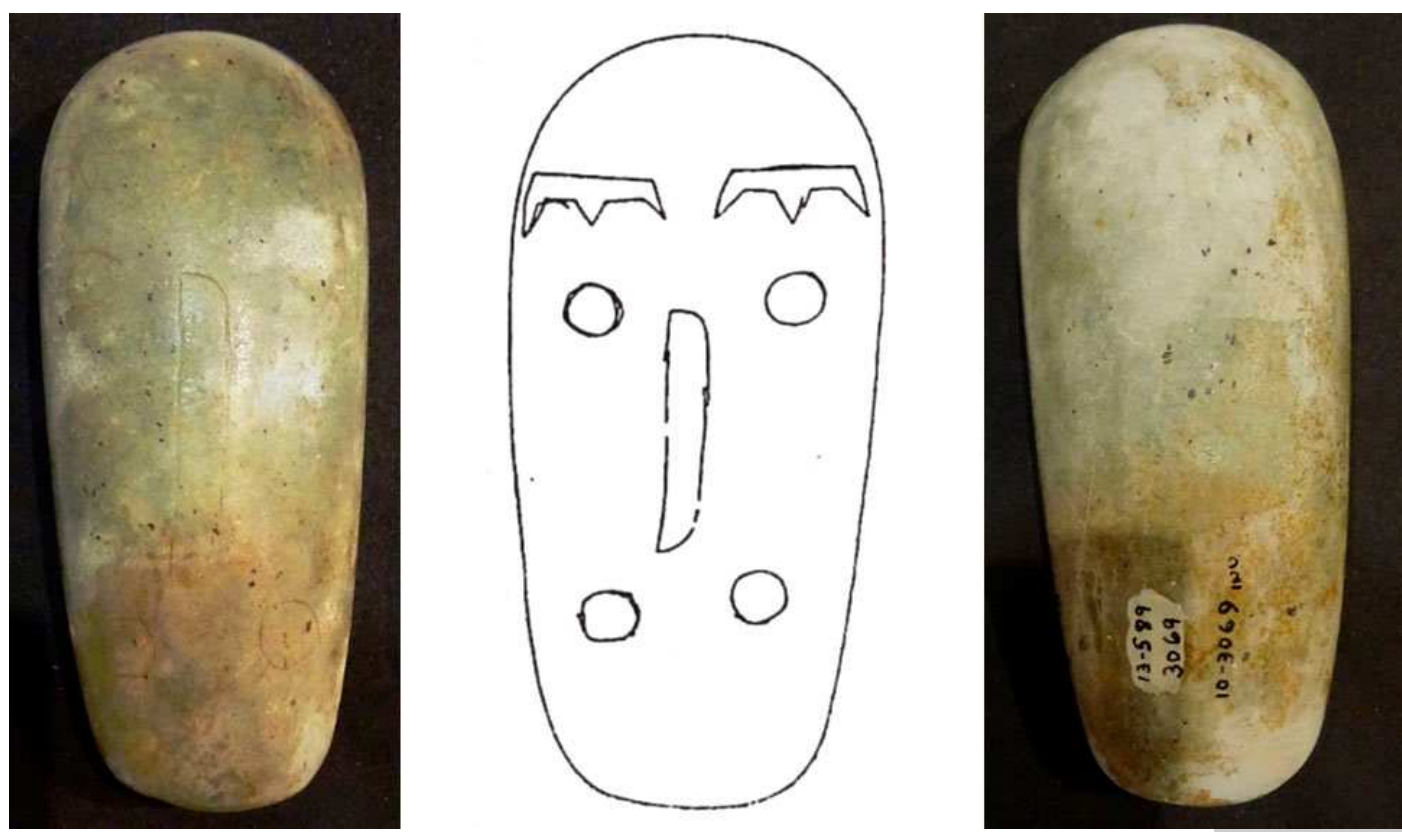

Figura 12. Hacha ofrenda 2 de La Venta (fotos del autor y dibujo tomado de Drucker 1959:141). 
El análisis de las huellas de manufactura en la superficie lisa, tanto en la parte trasera como la delantera de la pieza encontramos las bandas de $100 \mu \mathrm{m}$ características del desgaste con basalto y el pulido presenta líneas de entre 3.5 y 10 $\mu \mathrm{m}$ característicos del uso de arenisca para el pulido. La incisión no es nítida debido a la erosión en la que se encontró el hacha, pero se aprecian líneas de 0.6 y $1.3 \mu \mathrm{m}$ la utilización de la obsidiana como herramienta en su realización.

La tercera pieza es una figurilla que se encontró dentro de uno de los bultos mortuorios descubiertos en las excavaciones de 1942 dentro de la Tumba A del montículo A (Figura 13). Se trata de una figurilla humana esbelta ya que fue trabajada en un objeto delgado parece ser derivación de un hacha delgada.

Ya Drucker 1955 había observado que los extremos de muchos de los cortes de las piezas encontradas en La Venta se curvan hacia arriba en lugar de hacia abajo, observable en la figurilla que nos ocupa, esto indica que el corte se realizaba con sierras de algún material pétreo y que no se utilizó el método de piola y arena.

Las técnicas de manufactura observadas en las superficies lisas presentan desgaste con arenisca al presentar las bandas características de este material de 3.5 a $10 \mu \mathrm{m}$ (Figura 14). Tanto las incisiones como el corte muestran huellas de la utilización de obsidiana. Encontramos que, como muchas de las piezas que llevan muchos años en los museos, con limpiezas y mantenimientos diversos, las huellas de manufactura son menos evidentes. Las perforaciones muestran el uso de algún instrumento tubular y abrasivos, en este caso parece polvo de pedernal (Figura 15). 
Clio Arqueológica 2020, V35N2, p.78-121, MEDINA DOI: 10.20891/clio.V35V2p78-121
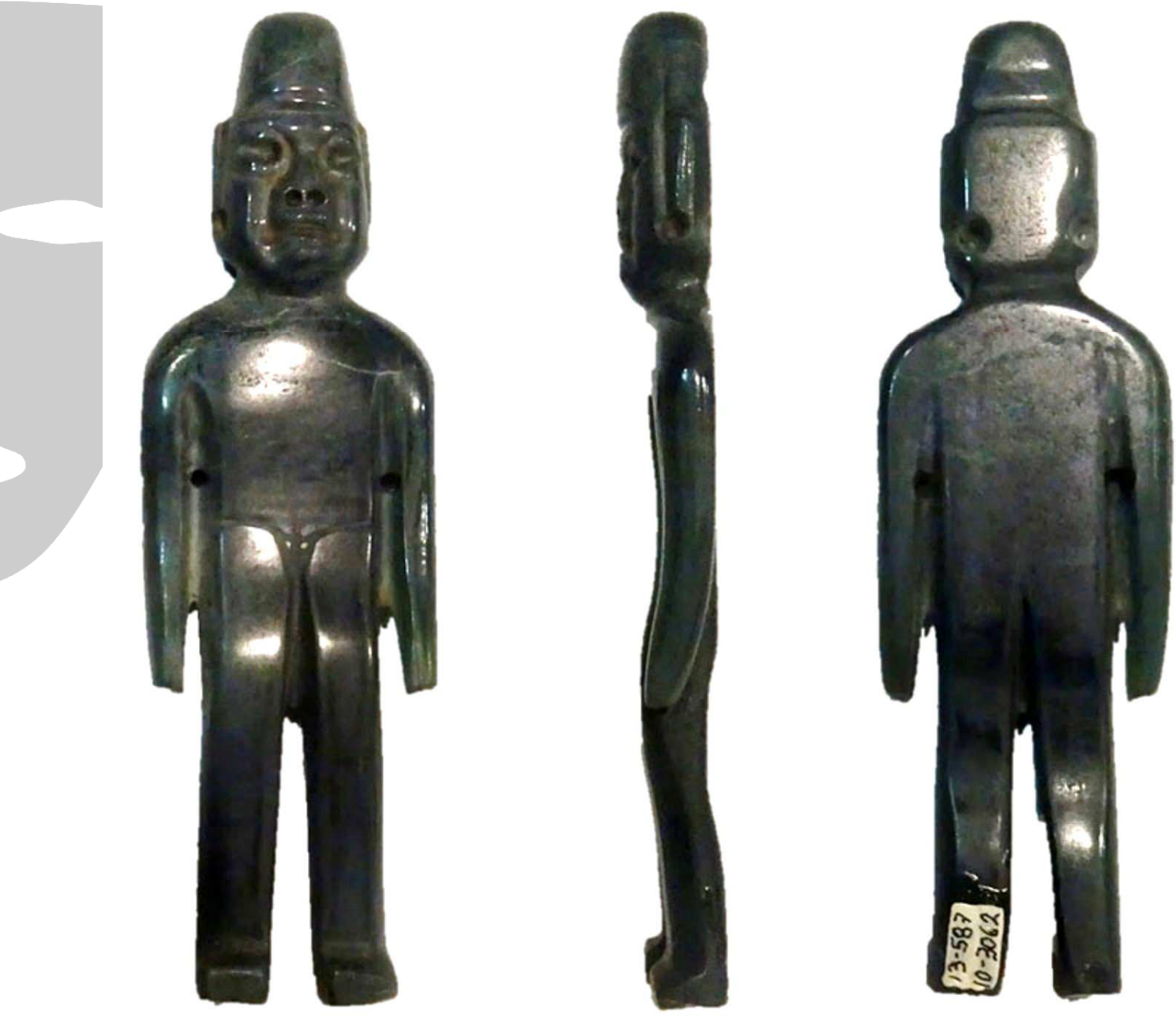

C $\underset{\text { Arqueológica }}{\boldsymbol{C}} \stackrel{0}{0}$

Figura 13. Figurilla dentro de la tumba de basalto de La Venta.

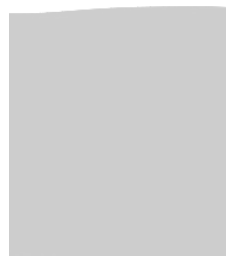



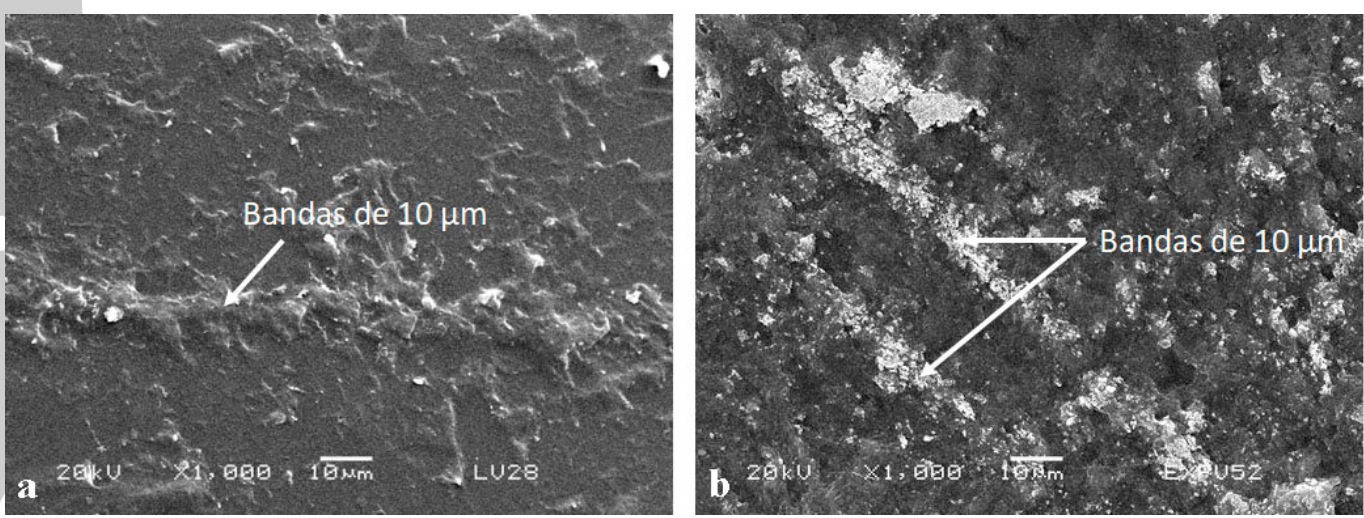

Figura 14. Análisis de superficies de figurilla de La Venta (a) comparada con desgaste experimental con arenisca (b).
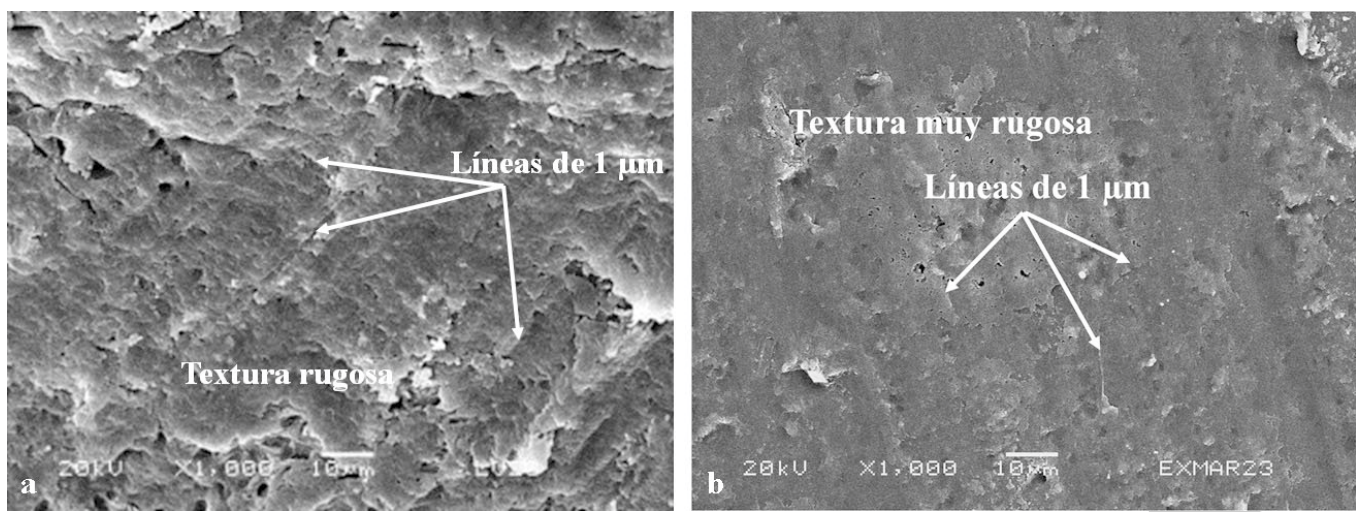

Figura 15. Análisis de perforaciones de figurilla de La Venta (a) comparada con horadación experimental con polvo de pedernal y carrizo (b). 
La cuarta pieza de este sitio es un mango de punzón (Figura 16), fue encontrado también como la figurilla anterior en la tumba A. Se encontraba en el bulto mortuorio número dos, asociado a la figurilla de la mujer sedente con espejo de hematita y a una punta de raya de jade entre otros objetos. Tiene una perforación bicónica en la parte baja trasera cerca del elemento cilíndrico, al parecer para amarrar algún elemento puntiagudo como una espina de maguey o quizá una espina de raya. La perforación fue igualmente a la figurilla anterior por medio de algún un instrumento tubular y abrasivos. El aspecto lustroso de la pieza y el color la convierte en una de las piezas con mejor acabado de este acervo.
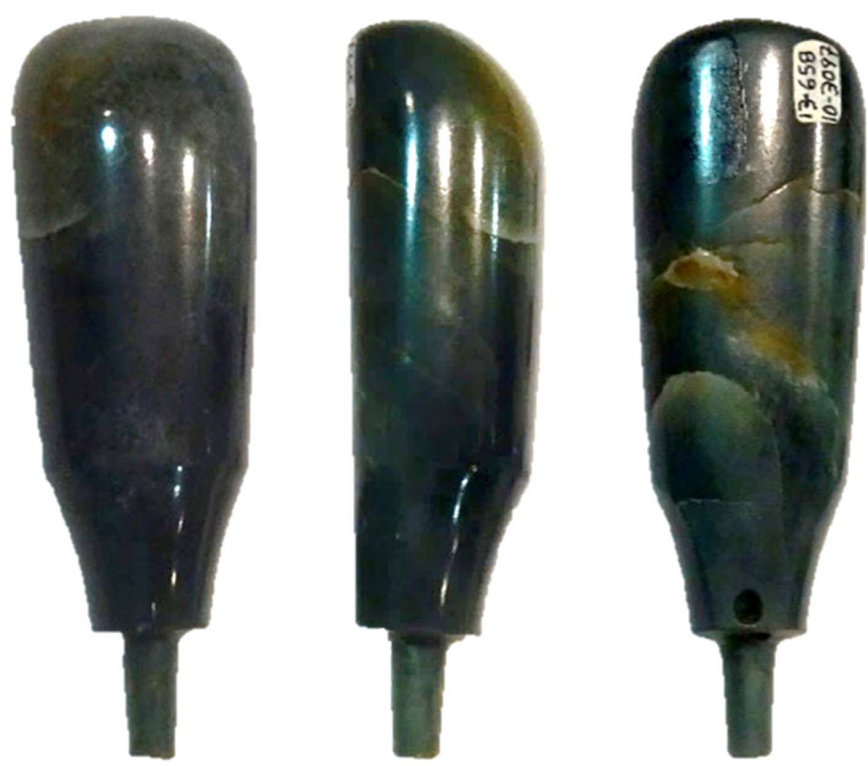

Figura 16. Mango de punzón, inventario \#103097 del MNA. 
La superficie presenta desgaste con basalto con las bandas de $100 \mu \mathrm{m}$ características de este tipo de huellas, mientras que el pulido muestra huellas de arenisca con líneas de entre 3.5 y $10 \mu \mathrm{m}$ y bruñido fue con piel que le dio ese aspecto lustroso y brillante.

Las últimas piezas analizadas procedentes de La Venta son tres hachas que se encontraron en una ofrenda localizada a $3.85 \mathrm{~m}$ de profundidad al sur del sarcófago denominado tumba b o monumento 6 de La Venta, la ofrenda constaba de alrededor de 37 hachas puestas en forma cruciforme. Entre ellas tres con decoración incisa, las cuales observaremos a continuación.

La primera hacha analizada de la Fase IV es un de forma petaloide incisa, la cual representa un personaje esquematizado en la superficie frontal la cual cuenta con dos concavidades. Se observan claramente sus ojos y manos, porta una banda con elementos conícos y por debajo de los ojos se observan dos elementos petaloides; en la parte baja y central del hacha hay unas concavidades donde están represantadas sus manos portando algún tipo de manopla puntiaguda. El hacha parece ser de jadeíta, presenta una coloración blanca-grisácea con un acabado lustroso.

La superficie presenta huellas de desgaste y pulido con arenisca, el bruñido es un trabajo con piel y otro material no identificado, el cual se presenta dejando huellas ovaladas deformes que se aprecian en las ampliaciones de 1000X y lo observamos 
en algunas de las piezas de La Venta y Arroyo Pesquero. Las incisiones presentan las huellas características del trabajo con obsidiana.

La segunda hacha incisa de esta fase tiene una representación fitomorfa incisa, relacionado con el maíz (JORALEMON, 1976; TAUBE, 1996). Lo interesante es que en la cara opuesta a la incisión muestra que se había trabajado anteriormente, parece una reutilización en la cual se borró lo que se había representado anteriormente, queda solo una pequeña huella visible de un elemento ovalado apenas perceptible en la parte superior del hacha y el trabajo de concavidades que van del centro hacia los costados como se encuentran en el frente del hacha anterior. $\mathrm{Su}$ color es de tonalidades cremas, grises claros y verdes (Figura 17).
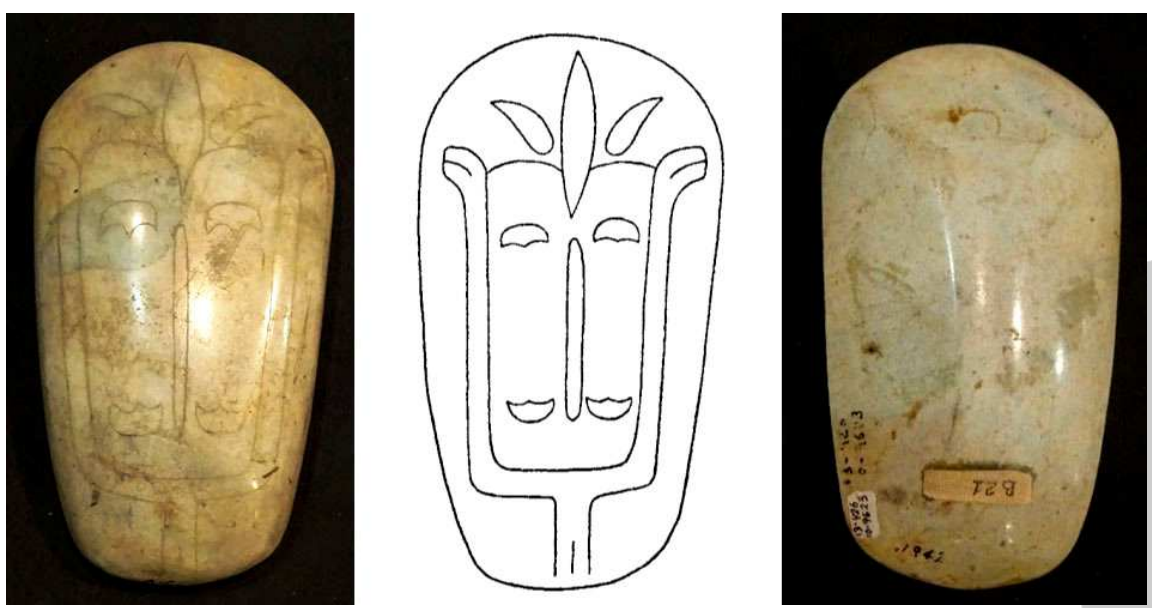

Figura 17. Hacha incisa de La Venta. (Fotos del autor y dibujo tomado de DRUCKER 1952: 165). 
El trabajo en la superficie presenta las huellas de manufactura de arenisca y algunos rastros de pulido con jade y bruñido con piel. La incisión muestra las líneas características, de nuevo, de la obsidiana.

La tercera hacha de este grupo con decoración incisa muestra tonalidades crema con algunos amarillos y grises claros. No presenta las texturas lustrosas como las dos anteriores debido, probablemente al material en el que fue realizado. Su forma petaloide de punta asimétrica.

La superficie lisa presenta al igual que la anterior un desgaste con arenisca, pulido con jade y bruñido con piel. La incisión muestra las líneas de 0.6 y a $1.3 \mu \mathrm{m}$ características de la obsidiana.

\section{Arroyo Pesquero}

De Arroyo Pesquero tendremos el análisis de las piezas que se encuentran en el Museo de Antropología de Xalapa llevadas por el arqueólogo Manuel Torres en 1969 reportadas por Medellín (1971) como piezas procedentes del sitio. También analizamos una descubierta en 2012 por el proyecto Arqueológico Arroyo Pesquero (PAAP), dirigido por Carl Wendt (WENDT et al., 2014). En total se analizaron de este sitio 12 piezas (Tabla 5): 2 figurillas, 3 hachas, 6 máscaras y un posible mango de cetro o de perforador. 
Clio Arqueológica 2020, V35N2, p.78-121, MEDINA

DOI: $10.20891 /$ clio.V35V2p78-121

\begin{tabular}{|c|c|c|c|c|}
\hline Id & Inv & Forma & Año de Hallazgo & Foto \\
\hline 1 & PAAP2012 I & $\begin{array}{l}\text { Cabeza de cetro o mango de } \\
\text { punzón }\end{array}$ & 2012 & \\
\hline 2 & 4015 & Figurilla & 1969 & \\
\hline 3 & 4016 & Figurilla & 1969 & \\
\hline 4 & 4008 & Máscara & 1969 & \\
\hline 5 & 4009 & Máscara & 1969 & \\
\hline 6 & 4010 & Máscara & 1969 & \\
\hline 7 & 4013 & Máscara & 1969 & \\
\hline 8 & 4014 & Máscara & 1969 & \\
\hline 9 & PJ 12134 & Máscara & 1969 & \\
\hline 10 & 4012 & Hacha & 1969 & \\
\hline 12 & 12035 & Hacha & 1969 & \\
\hline 13 & $121061 / 3$ & Hacha & 1969 & \\
\hline
\end{tabular}

Tabla 5. Piezas analizadas del sitio Arroyo Pesquero. 
La primera pieza que haremos mención es la encontrada en el Proyecto Arqueológico Arroyo Pesquero (PAAP) en 2012. Es un objeto de color café anaranjado con algunas manchas blancas que mide $8.7 \mathrm{~cm}$ de altura y $2.5 \mathrm{~cm}$ en su parte más ancha, de 3.20 de peso específico. Al igual que muchos otros objetos de piedra atribuidos a Arroyo Pesquero, este ejemplar está altamente pulido y alisado, con diseños tallados y líneas incisas con una pátina café la cual está presente en la mayoría de las esculturas de este sitio. La escultura está realizada en jadeíta como lo reportaron los estudios realizados por el laboratorio de LANCIC dirigido por José Luis Ruvalcaba del Instituto de Física de la UNAM.

En su parte inferior, el artefacto se compone de una especie de tallo cilíndrico el cual está dividido en tres lados por unas acanaladuras. Cada uno de estos lados, tiene dos elementos apilados de forma rectangular. La línea superior de estos elementos tiene una hendidura en forma de $\mathrm{V}$ en el centro y la línea inferior hay unas líneas incisas onduladas en contraposición a esta V. En la parte superior de la pieza sobresale un elemento cónico. (Figura 18).

La superficie muestra un pulido con arenisca de grano fino y bruñido con piel; mientras que las incisiones mostraron las huellas características de la obsidiana (Figura 19). 

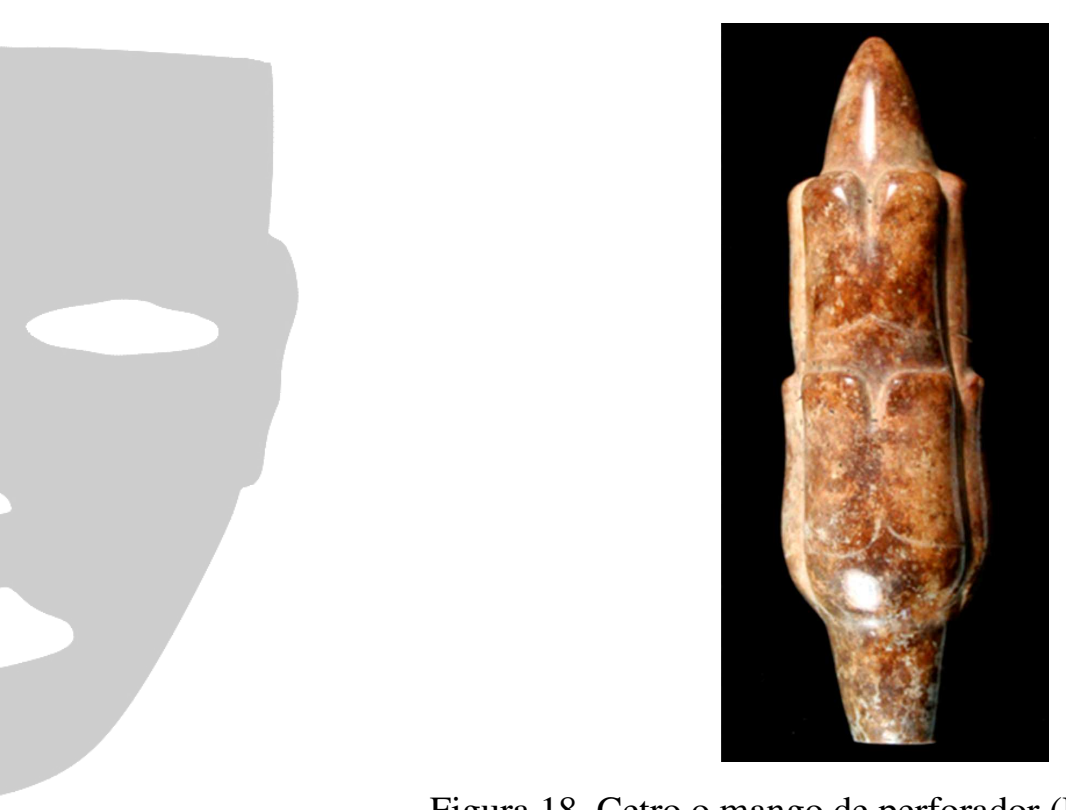

Figura 18. Cetro o mango de perforador (Foto Carl Wendt).
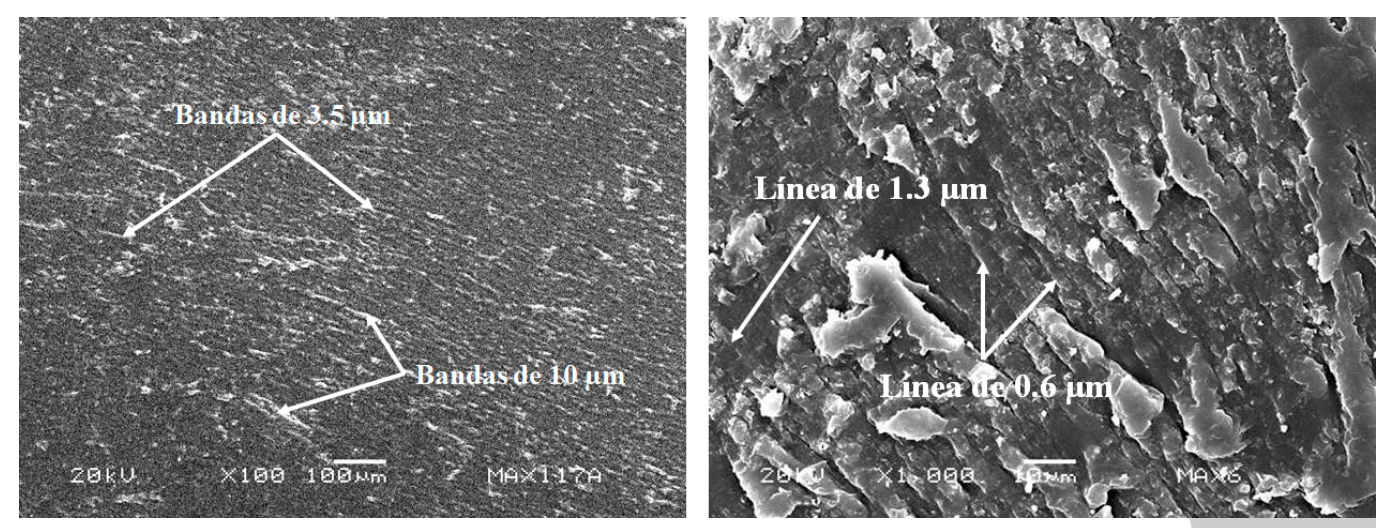

Figura 19. Superficie (a) e incisión del cetro de Arroyo Pesquero. 
La siguiente pieza es una figurilla de un personaje erguido con tocado (Figura 20), la cual presenta huellas de manufactura de arenisca en su superficie pulida. El bruñido no es claro, se observó muy poca textura en las muestras analizadas. Las incisiones fueron realizadas con obsidiana y la pieza presenta la pátina característica de Arroyo Pesquero en toda la pieza.
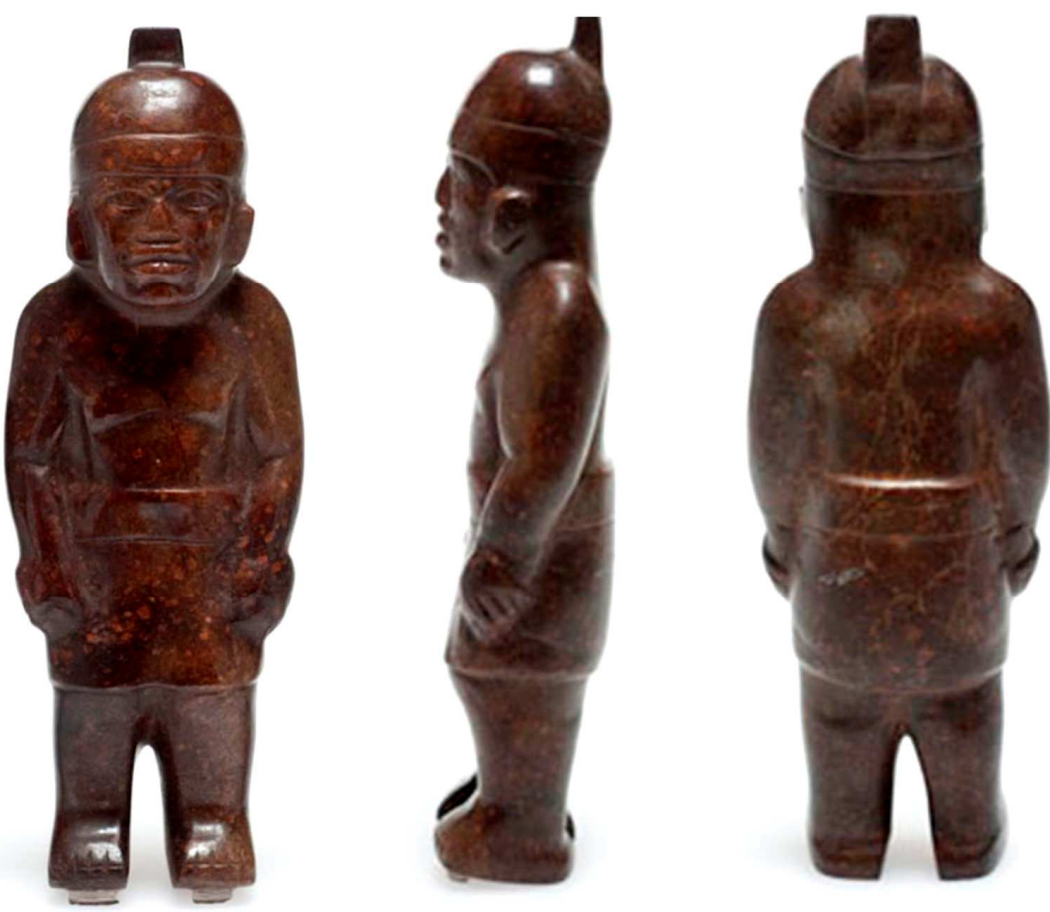

Figura 20. Figurilla erguida de Arroyo Pesquero. 
La tercera pieza es también una figurilla de un personaje erguido esquematizado (Figura 21). No tiene el acabado y detalle de la figurilla anterior. Tiene una representación incisa en la parte trasera de otro personaje inerte, como si se tratara de la piel de un desollado. Presenta evidencia de haber sido anteriormente un hacha, observable la parte superior de la cabeza donde se encontraba la parte distal. La superficie fue trabajada con arenisca, el bruñido presenta el mismo acabado encontrado en algunas piezas de La Venta, mientras que las incisiones fueron realizadas con obsidiana (Figura 22). El ombligo y los ojos fueron realizados con ligeras perforaciones las cuales presentan huellas de la utilización de abrasivos realizados con un instrumento tubular. La patina café, característica del sitio está presente en la mayor parte de la escultura.
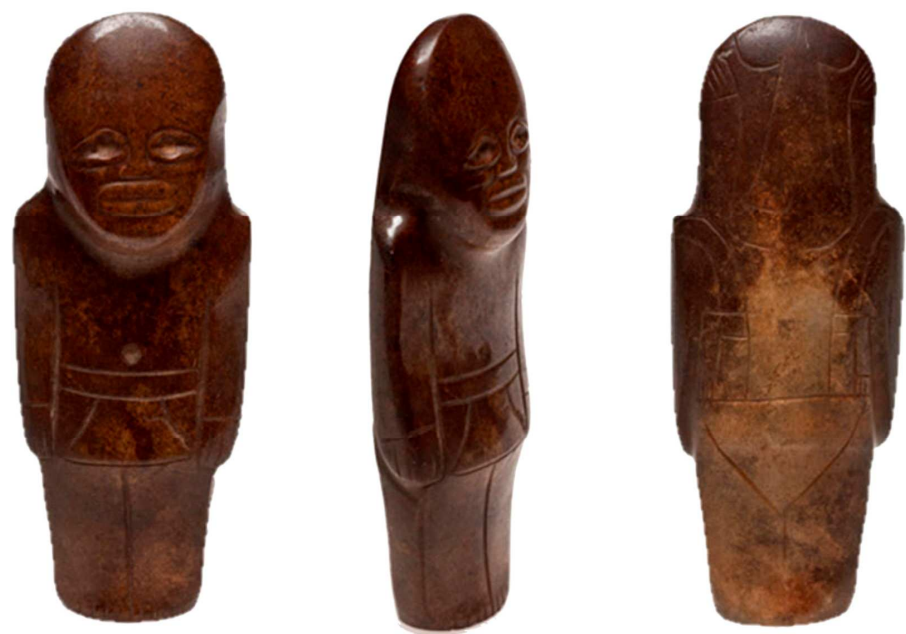

Figura 21. Figurilla esquemática de Arroyo Pesquero. 

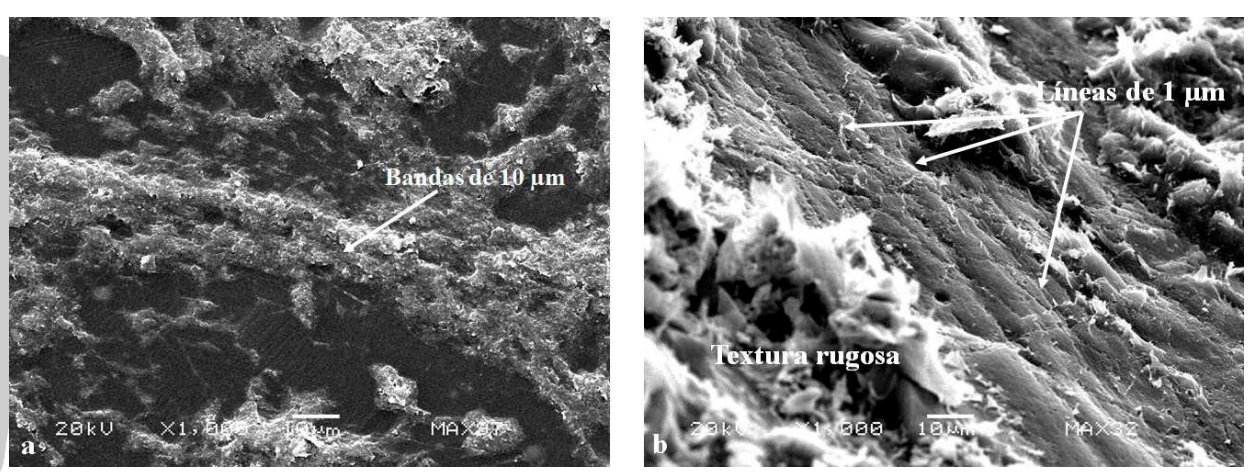

Figura 22. Huellas de superficie (a) e incisión (b) de la figurilla esquemática de Arroyo Pesquero.

Las siguientes piezas analizadas fueron 6 máscaras procedentes del sitio Arroyo Pesquero (Figura 23):

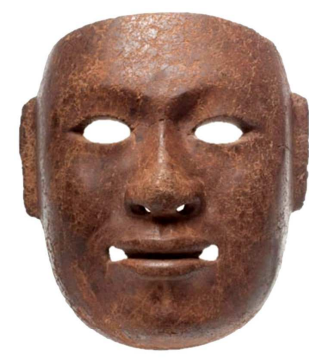

a

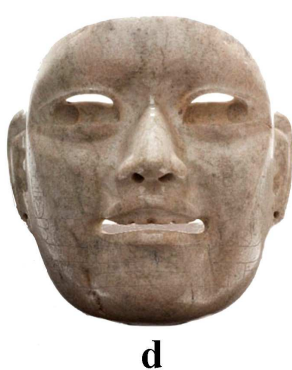

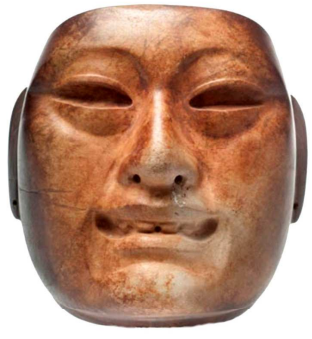

b

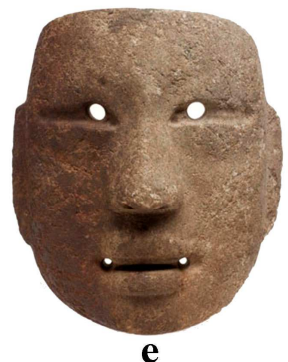

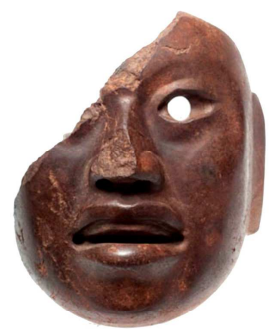

c

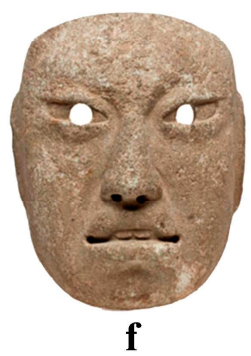

Figura 23. Máscaras analizadas de Arroyo Pesquero. 
La primera es de color café con rastros de algún pigmento rojo en la superficie interna de la máscara (Figura 23a). Presenta perforaciones para sujeción, además de que las orbitas de los ojos están completamente liberadas en forma oval. Presenta perforaciones que traspasan la máscara en las fosas nasales y en los extremos de la boca. Como aparece en la totalidad de las máscaras de Arroyo Pesquero analizadas en este trabajo, la máscara presenta un hueco en toda la parte trasera dejando un contorno cerrado en todo el perímetro del rostro, a diferencia de las máscaras teotihuacanas que muestran una abertura en la parte superior que permite el desgaste en una de las etapas de la cadena productiva propuesta por Gazzola (2009). La superficie presenta un pulido con arenisca, pero el bruñido no es claro, ya que la máscara presenta cierta erosión lo que provoca superficies rugosas. Las perforaciones presentaron desgaste con abrasivos de diferentes calidades.

La segunda es la máscara más pequeña de las seis que, sin embargo, tiene el hueco característico de las máscaras en piedra del sitio además de una cavidad para la nariz, las orbitas oculares y la boca no tiene abertura. De color café con algunas superficies color crema y blanquecinas (Figura 23b). El trabajo en superficie presenta un pulido con arenisca y bruñido con piel, la incisión en obsidiana y la perforación con abrasivos en particular encontramos en una de ellas la utilización de polvo de pedernal.

La tercera máscara se encuentra fragmentada (Figura 23c), es de color café oscuro y presenta un trabajo en superficie de pulido con arenisca. Las perforaciones presentan huellas de trabajo con abrasivos y un instrumento tubular. 
La cuarta máscara es la de mejor calidad procedente del sitio, la cual no presenta la pátina característica de las otras piezas del sitio (Figura 23d). Es de color blanco lustroso con algunas tonalidades de verde y vetas grises claras. Presenta un trabajo en superficie de pulido con arenisca y bruñido con piel y otro material no identificado. La incisión muestra el trabajo en obsidiana y las perforaciones con polvo de pedernal.

La quinta máscara se encontró en un estado avanzado de erosión en el frente de la máscara color café grisáceo (Figura 23e). Es un ejemplo claro de como la pátina característica del sitio no se presenta siempre en todas las piezas. Es evidente en la esquina derecha de la parte trasera en la que se observa la línea de división donde se encuentra por un lado la patina café y por el otro no. Ello divide la parte que tuvo contacto con el material que provocó la pátina, probablemente por elementos ferrosos que se encuentran en el agua del arroyo donde se recuperó. Presenta perforaciones en ojos, nariz y boca. En cuanto a las técnicas de manufactura, la superficie de frente se encuentra erosionada, sin embargo podemos distinguir en supeficie lisa de la parte trasera el pulido con arenisca. Las perforaciones presentan huellas de polvo de pedernal taladradas con algún instrumento tubular.

La útima máscara analizada al igual que la anterior se encuentra con un superficie frontal rugosa y con un estado elevado de erosión (Figura 23f). Los resultados de las huellas de manufactura fueron buenos pese a las texturas erosionadas y se tomaron las muestras de las superficies mejor conservadas desgastadas con arenisca (Figura 24a). De hecho, todavía se observa algunas partes de la incisión que 
delimitaba el párpado del ojo o las incisiones en los dientes en la delimitación de las encías, todas presentaron las líneas características de la obsidiana (Figura 24b).
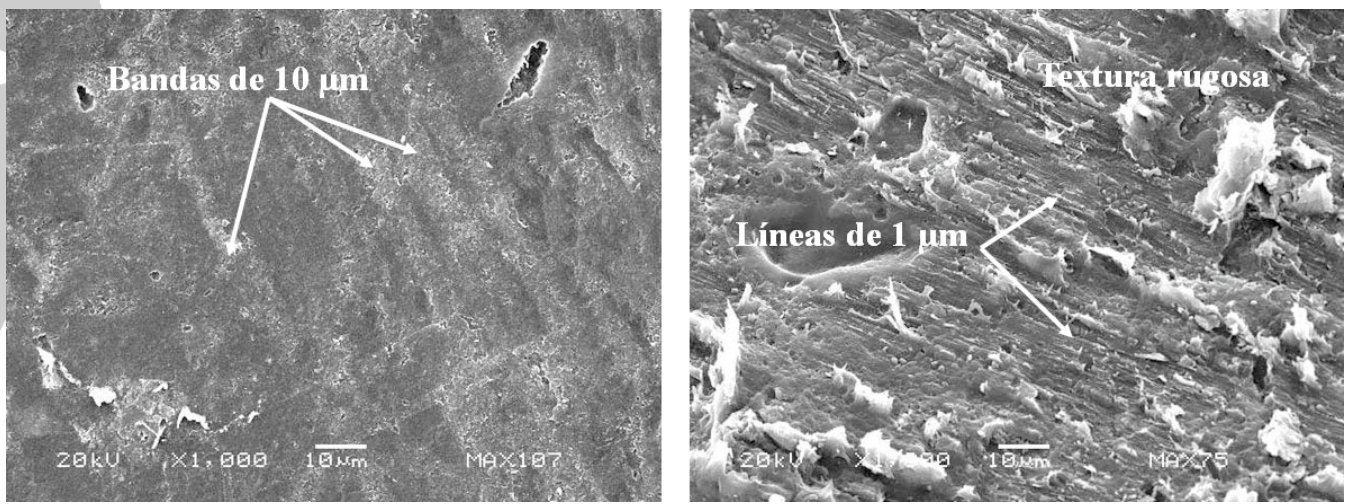

Figura 24. Análisis de huellas de máscara de Arroyo Pesquero: superficie (a) y perforación (b).

De Arroyo Pesquero se analizaron tres hachas en este trabajo (Figura 25):

La primera es incisa (Figura 25a), representado un personaje (Figura 25b). Tiene la pátina característica del sitio, presenta un acabado lustroso. La superficie muestra el pulido en arenisca (Figura 26a) y la incisión en obsidiana.

La segunda hacha es de color café atribuida a Arroyo Pesquero (Figura 25c); sin embargo, no se encuentra en la publicación de Medellín donde describe las piezas de Arroyo Pesquero. La superficie fue desgastada con basalto pulida con arenisca y bruñida con piel. 
La tercera hacha, al igual que el hacha anterior de Arroyo Pesquero, no es mencionada por Medellín Zenil, sin embargo, se le atribuye al sitio en las fichas del MAX y por eso la incluimos en este estudio (Figura 25d). Las muestras de las huellas de manufactura de la superficie de esta hacha indican un pulido con arenisca (Figura 26b).

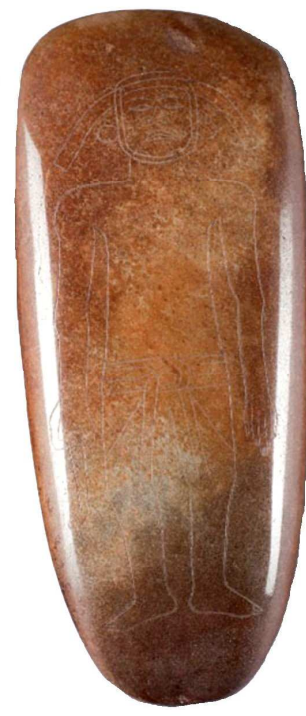

a

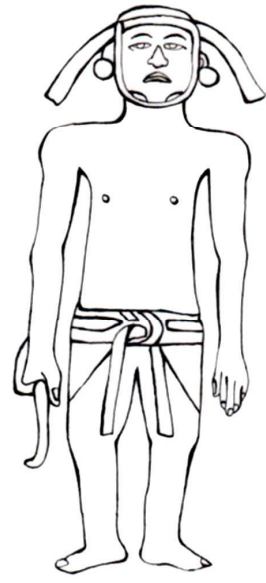

b

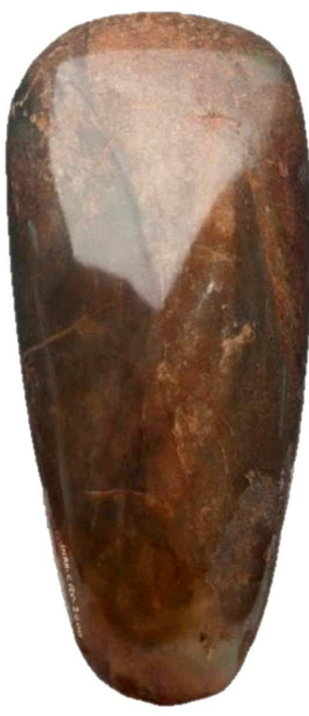

c

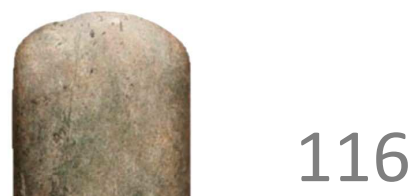

Figura 25. Hachas analizadas en Arroyo Pesquero: hacha incisa (a-b) y lisas (c-d). 

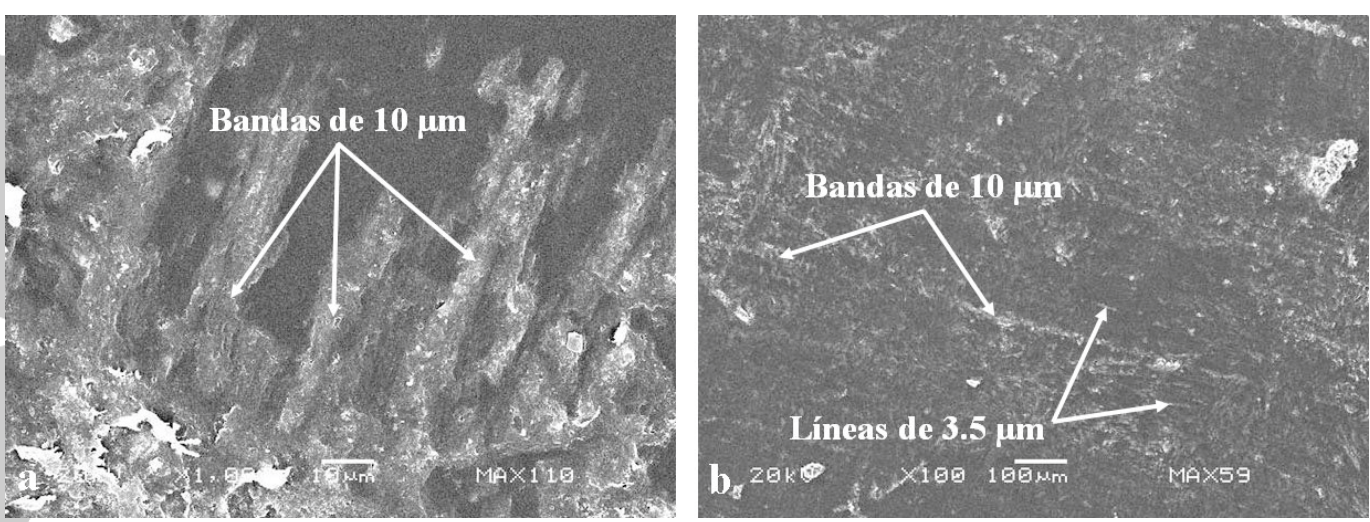

Figura 26. Análisis de superficies de hachas de Arroyo Pesquero desgastadas con arenisca.

\section{DISCUSIÓN Y CONCLUSIONES}

Los 71 artefactos que conforman el presente estudio procedentes de 4 sitios olmecas son insuficientes para observar tradiciones locales e interacciones con otras regiones y sitios a partir de este tipo de materiales. No obstante, podemos observar ciertas constantes y la utilización de materiales precisos que se utilizaron en su manufactura.

Para los sitios de San Lorenzo y Loma del Zapote observamos una concentración mayoritaria para la Fase San Lorenzo B. Las hachas analizadas de estos sitios presentan, las más tempranas, desgaste y pulido con arenisca. Para la única de la fase San Lorenzo A encontramos la utilización de caliza para el desgaste. Para la fase de San Lorenzo B donde se concentran la mayor cantidad de hachas observamos un trabajo de desgaste con basalto y pulido con arenisca y en dos casos el pulido es con jade. 
Podemos decir que la mayoría de las piezas de San Lorenzo y Loma del Zapote presentan un trabajo de pulido con areniscas algunas de ellas con granos gruesos. Para la fase San Lorenzo B pareciera que el trabajo de desgaste en las hachas se realizaba, preferentemente con basalto, pulido con arenisca y bruñido con piel. Las perforaciones no tuvieron buenos resultados debido a la presencia de residuos en superficie, las cuales provocan que las huellas muestren mucha textura y no puedan apreciarse correctamente.

En La Venta y Arroyo Pesquero encontramos un abrasivo no identificado que deja huellas particulares que no han podido ser replicadas en laboratorio. Por lo que se deben realizarse más experimentos en el bruñido para identificarlo.

La homogeneidad del trabajo de obsidiana para las incisiones en los trabajos de la Costa del Golfo es de llamar la atención y la uniformidad en el uso de instrumentos tubulares para la perforación, aunque los abrasivos para realizarlas pudieran cambiar. En algunos casos se hacía con polvo de pedernal.

En los sitios analizados hay una clara utilización de piedra verde para las esculturas, pero no es predominante, hay la búsqueda de colores claros, cremas, blancos y marrones. Algunas etapas de elaboración de las piezas probablemente se realizaron en San Lorenzo y La Venta, ya que se encontraron en ellos núcleos de perforación.

Podemos decir con esta muestra que la tradición lapidaria en el Golfo de México fue variando temporalmente y algunas técnicas pasaron de generación en generación; sin embargo, el cambio no es claro con las muestras analizadas hasta el 
momento. Encontramos algunos desgastes con basalto desde fechas tempranas y para el Formativo Medio comenzamos a ver el uso de jade para pulir ciertos objetos, pero la arenisca sigue siendo el material preferido para esta etapa antes del bruñido. Se requieren mayores análisis de piezas procedentes de contexto para afinar la tradición lapidaria olmeca del Golfo de México.

\section{REFERENCIAS BIBLIOGRÁFICAS ${ }^{2}$}

BEYER, H. 1927. “Tribes and temples”. El México Antiguo 2, 305-313.

BERNARD, H. 2018. "Les Hommes de Jade. Analyse techno-stylistique de la sculpture portable Olmèque". http://www.theses.fr/s133619.

CHENAULT, M. L. 1986. Technical analysis of Precolumbian Costa Rican jadeite and greenstone artifacts. Tesis Doctoral. University of Colorado.

CYPHERS, A., J. ZURITA Noguera, y M. L. RODRÍGUEZ. 2013. Retos y riesgos en la vida olmeca. México: Universidad Nacional Autónoma de México.

DRUCKER, P. 1952. "La Venta, Tabasco: A study of Olmec ceramics and art." Bureau of American Ethnology Bulletin 153, 1-257.

DRUCKER, P., R. F. HEIZER, y R. J. SQUIER. 1959. "Excavations at La Venta, Tabasco, 1955". Bureau of American Ethnology Bulletin 170, 138-142.

\footnotetext{
${ }^{2}$ Este trabajo no hubiera sido posible sin el apoyo de: Emiliano Melgar y Reyna Solís Taller de lapidaria del Templo Mayor, INAH. Museo de Antropología de Xalapa, Universidad Veracruzana. Carl Wendt, Fullerton State University of California, Chloé Andrieu y Brigitte Faugère. ArchAm, Université Paris 1 Panthéon Sorbonne, José Luis Ruvalcaba, Mayra Manrique, Laboratorio Nacional de Ciencias para la Investigación y Conservación del Patrimonio Cultural, Instituto de Física UNAM.
} 
GAZZOLA, J., 2009. "La cadena operativa en la fabricación de máscaras en los talleres de lapidaria de La Ventilla, Teotihuacan”. En L. Mirambell y L. González (eds.). Investigaciones Recientes Sobre La Lítica Arqueológica en México. México: Instituto National de Antropología e Historia, 66-77.

GONZÁLEZ Lauck, R. 1990. The 1984 Archaelogical Investigations at La Venta, Tabasco, Mexico. Tesis de doctorado, University of California.

GONZÁLEZ Lauck, R. 1994. "La antigua ciudad olmeca en La Venta, Tabasco". En J. Clark (ed.). Los Olmecas en Mesoamérica. México: Citibank-Ediciones Equilibrista, 92111 .

JORALEMON, P. D. 1976. "The Olmec dragon: a study in Pre-Columbian iconography". Origins of Religious Art and Iconography in Pre-Classic Mesoamerica. Los Angeles: University of California at Los Angeles Latin American Center Publications, 27-71.

MEDELLÍN Zenil, A. 1971 Monolitos olmecas y otros en el Museo de la Universidad de Veracruz. Corpus Antiquitatum Americanensium, Vol. 5. México: Instituto Nacional de Antropología e Historia, 1-53.

MELGAR Tísoc, E. R. 2004. "Proyecto La lapidaria del Templo Mayor: estilo y tradiciones tecnológicas. Propuesta de investigación”. México: Archivo del Museo del Templo Mayor, inédito.

MELGAR Tísoc, E. R., y R. B. SOLÍS Ciriaco. 2010. "Los artistas del jade en Mesoamérica y China: una comparación tecnológica". En La nueva Nao: de Formosa a América Latina. Reflexiones en torno al Bicentenario de las Independencias Latinoamericanas. Taipei: Universidad de Tamkang,

MELGAR, E. R., R.B. SOLIS y H. V. MONTERROSA. 2018. Piedras de fuego y agua turquesas y jades entre los nahuas. México: Museo del Templo Mayor, Instituto Nacional de Antropología e Historia.

SAVILLE, M. 1929. "Votive axes from ancient Mexico”. Indian Notes, VI, 266-299, 335342. 
STIRLING, M. W. 1939. "Discovering the New World's oldest dated work of man". National Geographic Magazine 76, 183-218.

STIRLING, M. W. 1943. "Stone Monuments of Southern Mexico". Bureau of American Ethnology Bulletin 138, 1-84.

TAUBE, K. 1996. "The Olmec maize god: the face of corn in Formative Mesoamerica". Anthropology and Aesthetics 29/30, 39-81.

VAILLANT. G. 1932. Some Resemblances in the Ceramics of Central and North America. Globe, Arizona: The Medallion.

WENDT, C. J., H. BERNARD, y J. DELSESCAUX. 2014. “A Middle Formative artifact excavated at Arroyo Pesquero, Veracruz”. Ancient Mesoamerica vol. 25, núm. 2, 309-316. 